PNL-3168

UC-11

\title{
An Evaluation of an In-Situ X-Ray Fluorescence Analyzer for Inorganic Pollutants in Sediments and Water Columns
}

N. A. Wogman

September 1979

Prepared for the U.S. Coast Guard under a Related Services Agreement with the U.S. Department of Energy

Contract EY-76-C-06-1830

Pacific Northwest Laboratory Operated for the U.S. Department of Energy by Battelle Memorial Institute 


\title{
NOTICE
}

This report was prepared as an account of work sponsored by the United States Government. Neither the United States nor the Department of Energy, nor any of their employees, nor any of their contractors. subcontractors, or their employees, makes any warranty, express or implied, or assumes any legal liability or responsibility for the accuracy, completeness or usefulness of any information, apparatus, product or process disclosed, or represents that its use would not infringe privately owned rights.

The views, opinions and conclusions contained in this report are those of the contractor and do not necessarily represent those of the United States Covernment or the United States. Department of Energy.

\author{
PACIFIC NORTHWEST LABORATORY \\ operated by \\ BATTELLE \\ for the \\ UNITED STATES DEPARTMENT OF ENERGY \\ Under Contract EY-76-C-06-1830
}
Printed in the United States of Ametica
Available from
National Technical Intormation Service
United States Department of Commerce
5285 Port Roval Road
Springfield, Virginia zms

Price: Printed Copys

: Microfiche $\$ 3.00$

NTIS

-Pages Selling Price

$\begin{array}{ll}001-025 & \$ 4.00 \\ 0.26-050 & 54.50 \\ 051-075 & 55.25 \\ 076.100 & 56.00 \\ 101-125 & 56.50 \\ 126-150 & \$ 7.25 \\ 151-175 & 58.00 \\ 176-2.00 & \$ 9.00 \\ 201-225 & 59.25 \\ 226-250 & 59.50 \\ 251-275 & 510.75 \\ 276-300 & 511.00\end{array}$




\section{5}

AN EVALUATION OF AN IN-SITU X-RAY FLUORESCENCE ANALYZER FOR INORGANIC POLLUTANTS IN SEDIMENTS AND WATER COLUMNS

N. A. Wogman

September 1979

Prepared for the U. S. Coast Guard under a Related Services Agreement with the U. S. Department of Energy

Contract EY-76-C-06-1830

Pacific Northwest Laboratory

Richland, Washington 99352 

TABLE OF CONTENTS

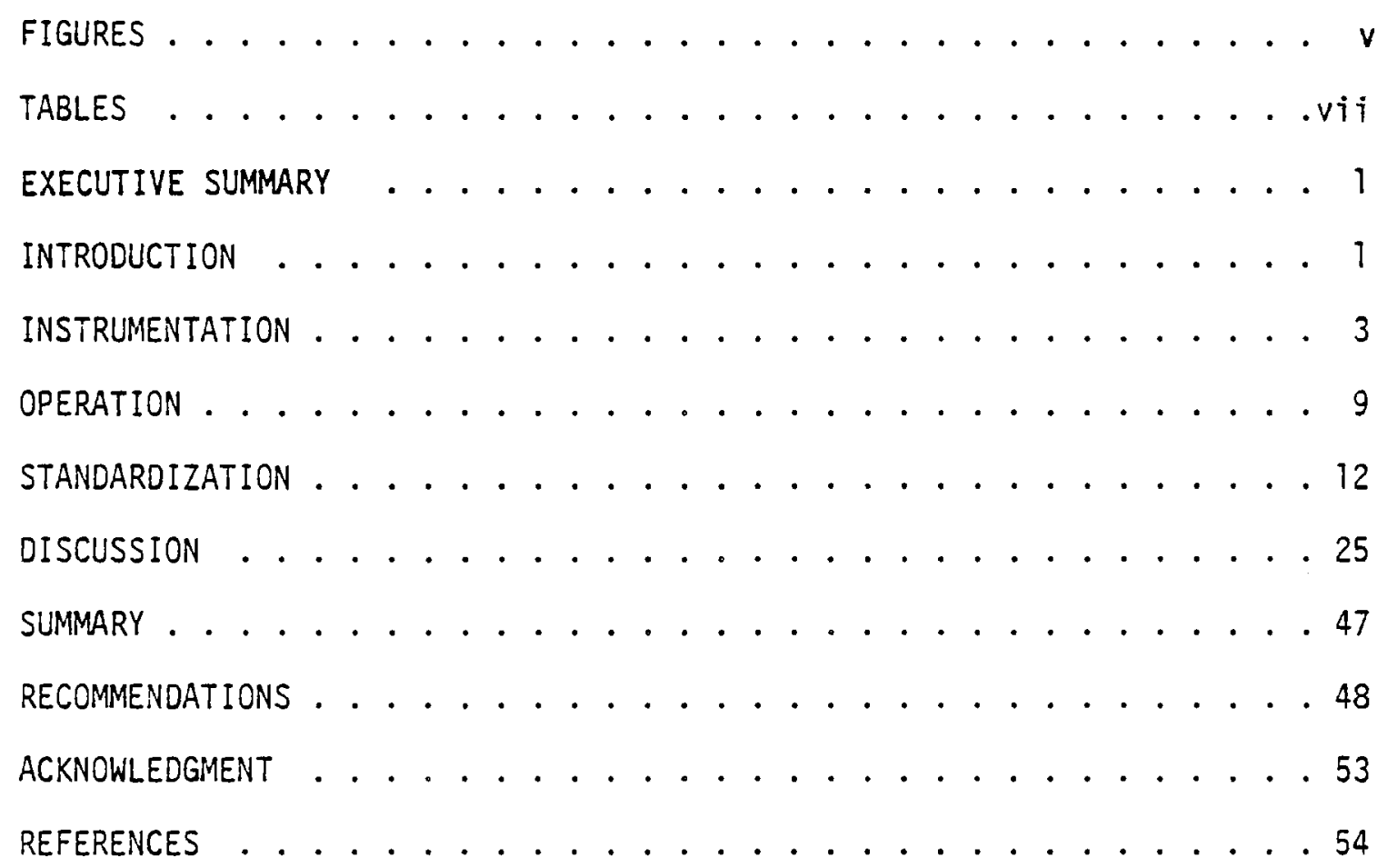




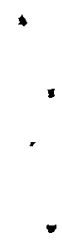




\section{FIGURES}

1. Schematic Representation of Detector, Collimator, Radio- . . . . . 4 active Source, Beryllium Window and the Sediment Sample

2. Electronics Used for In-Situ X-ray System Evaluation . . . . . . 6

3. In-Situ X-ray Fluorescence System Being Electronically . . . . . . 7 Checked Prior to Shipment

4. An In-Situ X-ray Fluorescence Detector Designed to Analyze . . . . .10 Inorganic Element Concentrations on Sediment Surfaces and in Water Columns

5. In-Situ X-ray Fluorescence Spectrometer Operating from . . . . . . . 11 an 8 Meter Surface Vessel

6. Locations in Lake Union Analyzed with In-Situ X-ray . . . . . . .13 Fluorescence Spectrometry for Inorganic Species

7. Locations in Lake Washington Analyzed with In-Situ . . . . . . . 14 Fluorescence Spectrometry for Inorganic Species

8. Locations in the Ship Canal Analyzed with In-Situ X-ray . . . . . 15 Fluorescence Spectrometry for Inorganic Species

9. Locations in Puget Sound at Point Defiance Analyzed with . . . . . 16 In-Situ X-ray Fluorescence Spectrometry for Inorganic Species

10. Locations in Puget Sound at Elliott Bay Analyzed with In-Situ . . 17 $X$-ray Fluorescence Spectrometry for Inorganic Species

11. The Relative Counting Efficiency of a Si(Li) Detector . . . . . . 20 for Photons Emitted by $\mathrm{Fe}, \mathrm{Cu}, \mathrm{Zn}, \mathrm{Rb}, \mathrm{Sr}$, and $\mathrm{Zr}$

Following ${ }^{109} \mathrm{Cd}$ Excitation

12. In-Situ X-ray Fluorescence Spectra of Ship Canal, . . . . . . . . 35 Washington Sediments Using a ${ }^{109} \mathrm{Cd}$ Excitation Source

13. In-Situ X-ray Fluorescence Spectra of Lake Union, . . . . . . . . .36 Washington Sediments Using a ${ }^{109} \mathrm{Cd}$ Excitation Source

14. In-Situ X-ray Fluorescence of Point Defiance, . . . . . . . . . . .37 Washington Sediments Using a $109 \mathrm{Cd}$ Excitation Source

15. In-Situ X-ray Fluorescence Spectra of Point Defiance, . . . . . . .38 Washington Sediments Using a ${ }^{109} \mathrm{Cd}$ Excitation Source 
FIGURES (Contd)

16. In-Situ X-ray Fluorescence Spectra of Elliott Bay, . . . . . . . . 39 Washington Sediments Using a ${ }^{109} \mathrm{Cd}$ Excitation Source

17. In-Situ X-ray Fluorescence Spectra of Elliott Bay, . . . . . . . 40 Washington Sediments Using a ${ }^{109} \mathrm{Cd}$ Excitation Source

18. In-Situ X-ray Fluorescence Spectra of Ship Canal, . . . . . . . . .41 Washington Sediments Using a ${ }^{109} \mathrm{Cd}$ Excitation Scurce

19. Pb Concentrations as a Function of Sediment Depth in the . . . . 45 Ship Canal, Washington 


\section{TABLES}

I. Measurement Parameters .................. . 18

II. Detection Sensitivities and Prominent $X$-ray Energy Lines . . . . . .21 for the In-Situ Seabed Analyzer

III. X-ray Energies as a Function of Elements . . . . . . . . . . .23

IV. A Comparison of Laboratory and In-Situ Standards . . . . . . . 24

V. Sample Location Descriptions in Lake Union, Seattle, . . . . . . .26 Washington

VI. Sample Location Descriptions in the Ship Canal, Seattle, . . . . . 27 Washington

VII. Sample Location Descriptions in Lake Washington, Seattle, . . . . .28 Washington

VIII. Sample Location Descriptions in Puget Sound at Point Defiance . . . 29 and Elliott Bay, Washington

IX. The Concentrations of 23 Elements in Surficial Sediments . . . . . .30 in Puget Sound as Determined by In-Situ $X$-ray Fluorescence Spectrometry

$x$. The Concentrations of 23 Elements in Surficial Sediments . . . . . . 31 in the Ship Canal as Determined by In-Situ X-ray Fluorescence Spectrometry

XI. The Concentrations of 23 Elements in Surficial Sediments . . . . . 32 in Lake Union as Determined by In-Situ X-ray Fluorescence Spectrometry

XII. The Concentrations of 23 Elements in Surficial Sediments. . . . . .33 in Lake Washington as Determined by In-Situ X-ray Fluorescence Spectrometry 
EVALUATION OF AN IN-SITU X-RAY FLUORESCENCE ANALYZER

FOR INORGANIC POLLUTANTS IN SEDIMENTS AND

WATER COLUMNS

\author{
N. A. Wogman \\ Pacific Northwest Laboratory \\ Richland, Washington 99352
}

\title{
EXECUTIVE SUMMARY
}

The applicability of an energy dispersive $X$-ray fluorescence spectrometer for measurement of trace elements in sediments and in water columns from coast Guard vessels has been investigated. This investigation was conducted in both freshwater and saltwater areas and included Puget Sound, Lake Washington, Lake Union, and the ship canal in the State of Washington. The spectrometer system consisted of a solid cryogen-cooled $\mathrm{Si}(\mathrm{Li})$ detector and a ${ }^{109} \mathrm{Cd}$ excitation source. Sediments and water columns were viewed through a $0.2 \mathrm{~mm}$ Be window. This study showed the feasibility of measuring trace elements at concentrations ranging from 20 to about $100 \mathrm{ppm}$. Measurements of this sensitivity with a $100 \mathrm{mCi}{ }^{109} \mathrm{Cd}$ source are possible for time intervals as short as 5 minutes. This in-situ measurement capability permits the on-site mapping of pollution and avoids the problem of sediment disturbance which is inherent in the collection of grab samples of the sediment surface. Recommendations for an improved analyzer system which are contained in the report included a detector assembly which could be towed, or allow continuous sediment surface analysis thereby recording the average composition of a large area. They also suggest improvements in on-site data handling such that concentrations of the trace elements of interest could be read out immediately following the measurement. In order to optimize the design and to construct a spectrometer system for in-situ measurements, we recommend a one-year program which would include further in-situ measurements and the actual development and construction of a field instrument.

\section{INTRODUCTION}

The release of energy-related pollutants to the world's waterways results in hundreds of square miles of polluted waters and sediments which require characterization for an evaluation of their spread and potential hazard to the marine and freshwater environment. $(1,2,3)$ The measurement of pollutants in sediments and water columns should ideally be accomplished by a system 
which continuously integrates element concentrations over broad areas, yet allows the analysis of specific elements at individual sites. Previous studies have shown that $X$-ray fluorescence spectrometry has an excellent potential for detecting inorganic pollutant elements. $(4,5-12)$ Some of these studies (6-10) represent the first attempt at utilizing $X$-ray fluorescence spectrometry for underwater analysis of inorganic pollutants in sediments, water columns, and as a function of sediment depth.

Prior to the development of an underwater $X$-ray spectrometer, pollutant element analysis was accomplished in the laboratory on materials which had been obtained by grab sampling. This latter technique creates errors in data interpretation since it integrates the entire pollutant sample--pollutant layers are folded into one sample. This destruction of pollutant layering does not allow the marine ecologist to verify the pollution concentrations at the sediment surface or as a function of sediment depth. In addition, grab sampling does not allow real time decisions to be made on where to sample. In studying soluble pollutants, this grab sample is entirely useless since its analysis is at a later time and thus corrective action cannot be taken in real time.

A new $X$-ray fluorescence system, which allows the in-situ inorganic analysis of sediment surfaces, water columns, and pollutant concentration profiles as a function of sediment depth, avoids these major problems. (6-10) The technique provides pollutant concentration measurements in 5 to $10 \mathrm{~min}$ periods at the 5 to $50 \mathrm{ppm}$ level for ten to thirty elements. This study discusses the evaluation and use of such a system for the in-situ inorganic element analysis of freshwater and marine sediments and waters using a surface vessel. 
This evaluation allowed a set of recommendations and experimental protocols to be developed for U. S. Coast Guard consideration of the in-situ X-ray fluorescence method.

\section{INSTRUMENTATION}

Energy-dispersive $X$-ray fluorescence analys is for determining elemental content of sedimentary material has been well established. (4,5) The normal procedure uses a beam of low-energy photons to induce characteristic $X$-ray emissions of elements in the samples of interest. These $X$-rays are then detected by a solid-state system yielding a pulse which is proportional to the $X$-ray energy. This technique has been adapted for underwater application using a ${ }^{109} \mathrm{Cd}$ source, an $80 \mathrm{~mm}^{2}$ silver collimator, and an $80 \mathrm{~mm}^{2} \mathrm{si}(\mathrm{Li})$ diode as the detector. $\left({ }^{8}\right)$

The ${ }^{109} \mathrm{Cd}$ source used in this evaluation was only $6 \mathrm{mCi}$. The originally developed instrument used $100 \mathrm{mCi}$ of $\left.109 \mathrm{Cd} .{ }^{8}\right)$ since this experiment was to evaluate the use of in-situ X-ray fluorescence techniques to U. S. Coast Guard problems, it was accomplished with an existing ${ }^{109} \mathrm{Cd}$ source for economy. A fresh $100 \mathrm{mCi}$ source would cost on the order of $\$ 5000$ and thus was not deemed necessary for this experiment.

In Figure 1 is shown a schematic representation of the detector, radioactive source, and external beryllium window used in the in-situ $X$-ray fluorescence system. The detector is composed of an $80 \mathrm{~mm}^{2} \mathrm{Si}(L i)$ system that is housed behind its own beryllium window. The present detector system was built by Princeton Gamma Tech in Princeton, New jersey. At this time they are the only U. S. vendor which will construct prototype systems such as this one. 


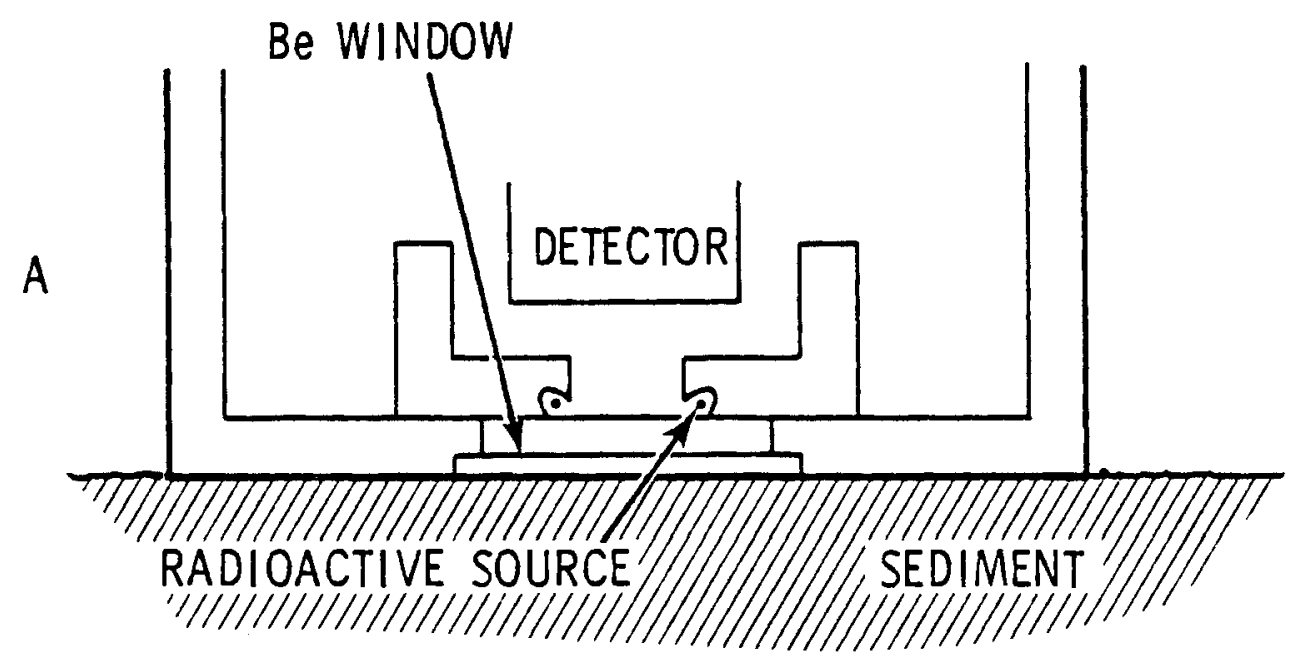

Figure 1 Schematic representation of detector, collimator, radioactive source, beryllium window and the sediment sample. 
The detector system is modified, however, by collimating the radioactive source behind a second beryllium window which serves to isolate the entire analysis system from the outside water pressure and sediment surface. The second beryllium window allows a defined detector/irradiator/source geometry to be maintained throughout the analysis. In addition, the beryllium isolation window can be broken and replaced in the field without destroying the detector assembly.

In Figure 2 are shown an analyzer (center), a tape deck (far right), and the electronics high voltage supplies (far left) used in evaluating the insitu $X$-ray system.

In Figure 3 are shown the electronics and complete detector system as they would reside in a laboratory prior to being packaged for shipment. The detector system is cooled with liquid nitrogen (LM) as shown by the LN dewar in the upper right-hand corner. The electronics package shown in the center is nomally checked with a small standard oscilloscope (far left) guaranteeing timing of the electronic pulses. Although other instrumentation can be used with this instrument for field analysis, this simple method of collecting data and storing it on tape for future reference allowed rapid assembly of data in this evaluation program. As will be seen later, recommendations have been made to modify the electronics package used for the $x$-ray fluorescence analys is for U. S. Coast Guard purposes.

The electronics used to store the field data for this evaluation was a portable 4096-word analyzer, Model 720, built by Tracor-Northern with a portable magnetic tape deck for data storage. A laboratory POP 11/35 computer with multi-disc memory capability was used to analyze the field data after its 


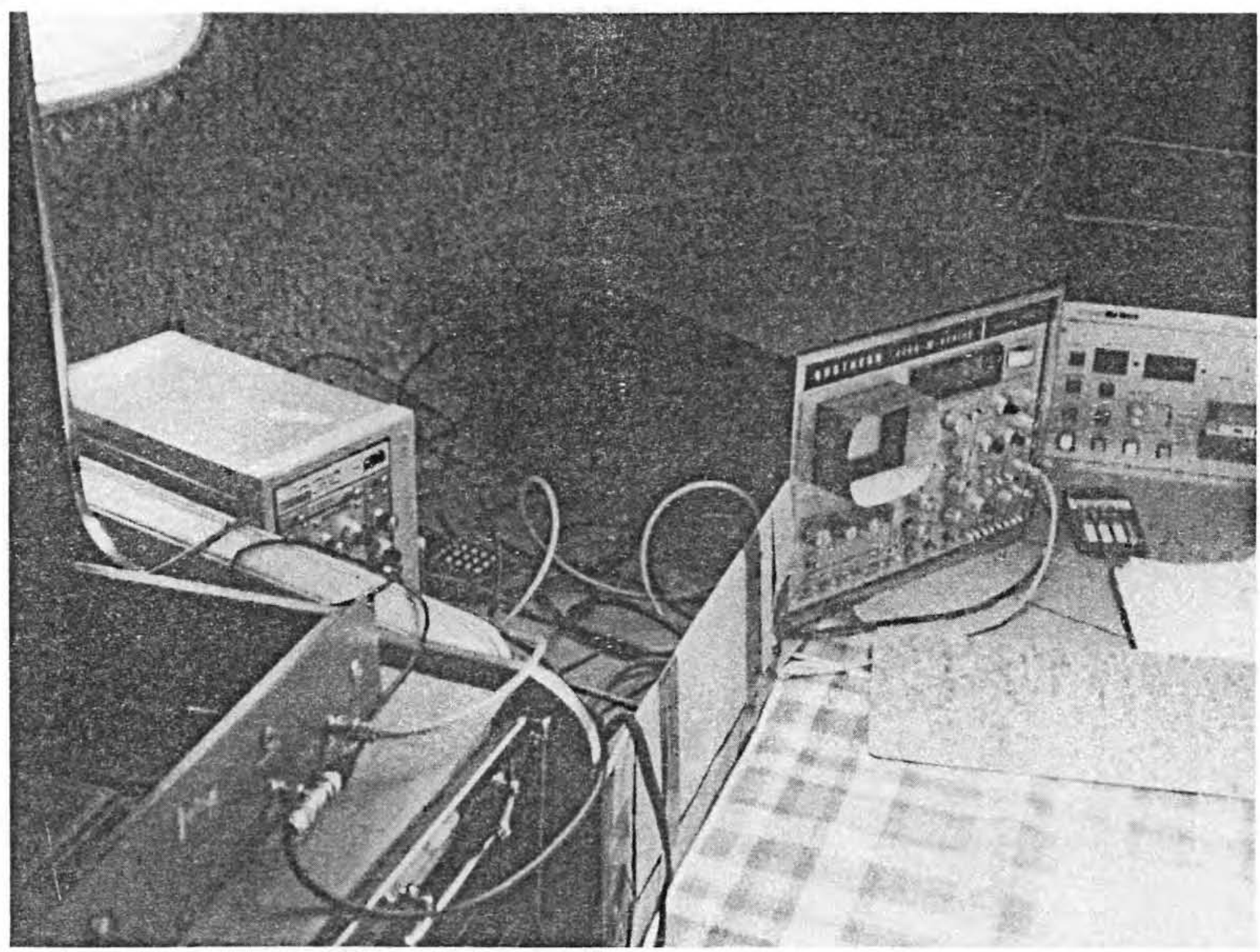

Figure 2. Electronics used for in-situ X-ray system evlauation 


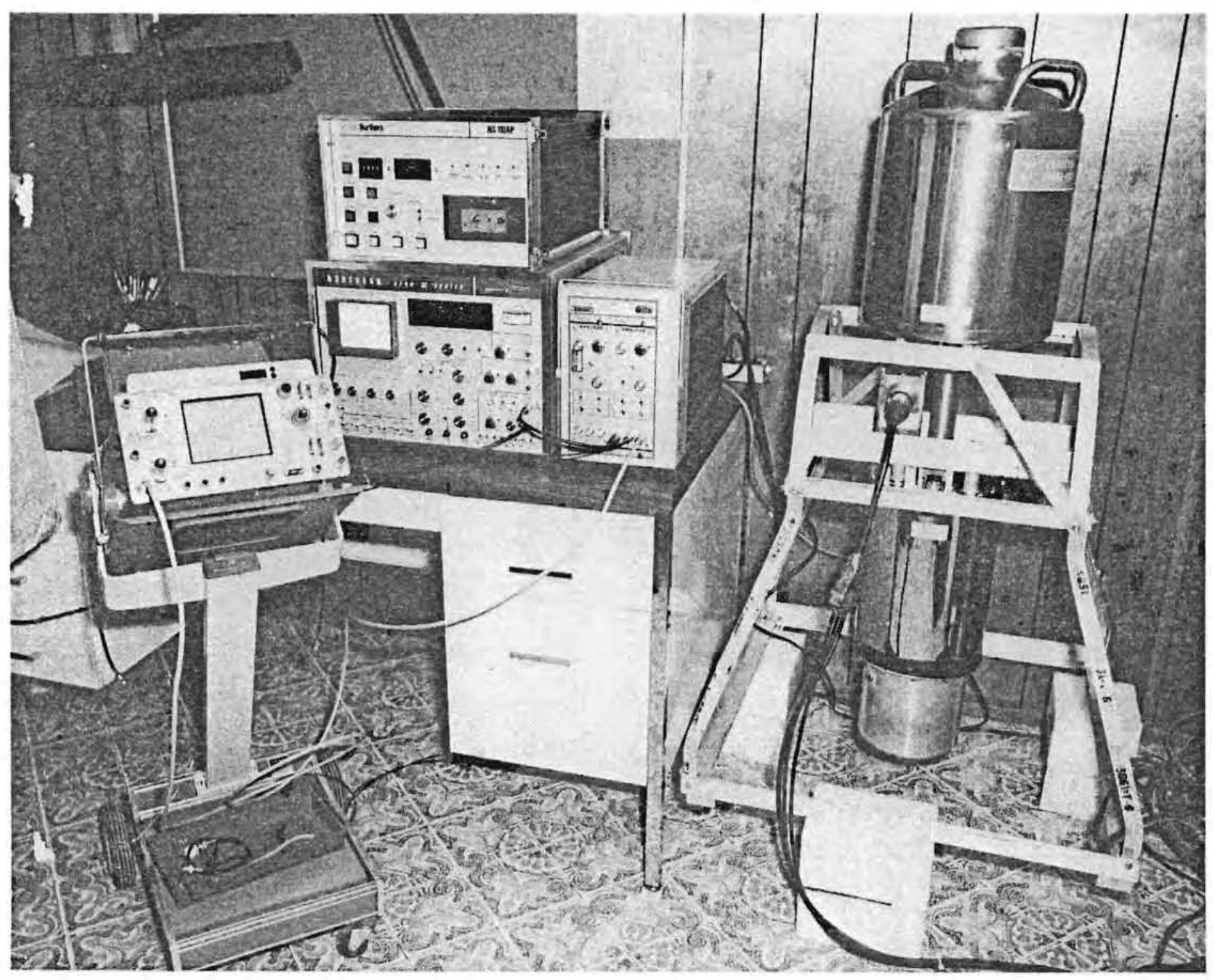

Figure 3. In-situ X-ray fluorescence system being electronically checked prior to shipment 
transfer by the magnetic tape cassette. The resolution of the prototype $X$-ray fluorescence system is 225 eV full width half maximum at $5.9 \mathrm{keV}$. This resolution is achieved with the spectrometer system underwater with 100 meters of cable. The system is cooled with a cryogen, freon-22, which is frozen with liquid nitrogen; it permits 24 hours of continuous subsurface operation.

The $s i(L i)$ detector is protected by a pair of beryllium windows as shown in Figure 1. The first $0.1 \mathrm{~mm}$ window protects the detector from atmospheric pressure. The second window, which varies from 0.2 to $1.0 \mathrm{~mm}$, depending on the water pressure to be encountered, protects the detector from its environs. The outside dimensions of the device are $70 \mathrm{~cm} \times 70 \mathrm{~cm} \times 85$ $\mathrm{cm}$ with an air weight of $40 \mathrm{~kg}$, and a water weight of $5 \mathrm{~kg}$. Although the system uses a radioisotopic source, it can be easily transported from state to state and handled in field experiments. Transportation and use are facilitated by notifying the state in which the study is to be performed and federal (U. S. Coast Guard) authorities that a sealed source of a given size is going to be operating in their area. [The X-ray fluorescence analyzer serves as the Department of Transportation (DOT) container for its radioisotopic source.] The personnel operating the $x$-ray fluorescence system must, of course, have radiation work procedures available and radiation handling training. This is mandated by both state and federal authorities for use of isotopic sources and proves to be no problem. The radioactive sources are doubly encapsulated and do not provide a hazard to man. The insitu systems always contain either pingers to determine location if lost or 
additional safety lines in case the primary line to the system deteriorates.

The effect of electronic noise on the spectrometer has been studied since it has occasionally proven to be a problem. In this experiment it did not degrade the spectrometer resolution beyond that normally expected due to the long cable connecting the detector and its amplifier.

\section{OPERATION}

The prototype energy-dispersive $X$-ray fluorescence analyzer which has been developed at Battelle-Northwest (6-9) for the analysis of pollutant elements on sediment surfaces was used to analyze elemental concentrations in waters and sediments in the State of Washington. The X-ray fluorescence assembly is shown in Figure 4.

The system was evaluated from a small 8 meter surface vessel containing portable generators and voltage stabilizers. (See Figure 5) Although the underwater in-situ $X$-ray fluorescence device can be handled by a boat as small as 8 meters as illustrated in the present study, a larger boat has more access for electronics. However, the smaller the boat, the easier access one has to dockages, moorages, and actual pollutant points of interest in congested harbor conditions. A winch is required for lifting the device from the boat into the water. The analyzer (Figure 2) recorded the spectral response of the detector for 5 to $100 \mathrm{~min}$, after which the spectrometer was lifted back to the boat and a new location pursued. While the vessel was preparing to move, the analyzer was transferring its spectral data to a portable magnetic tape deck. After data transfer, some 20 regions containing integrated counts from the elemental peak areas could automatically be read 


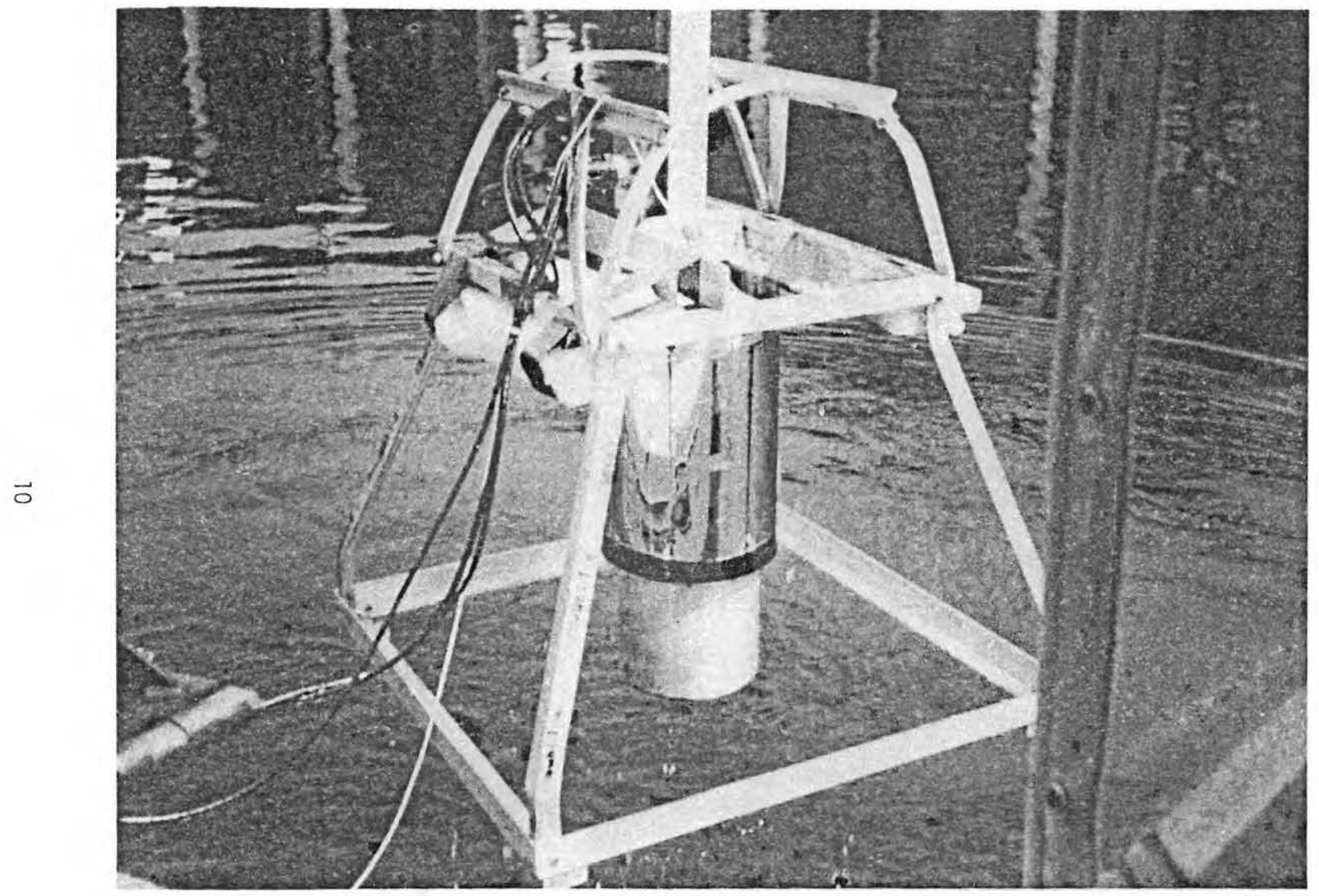

Figure 4. An in-situ X-ray fluorescence detector designed to analyze inorganic element concentrations on sediment surfaces and in water columns 


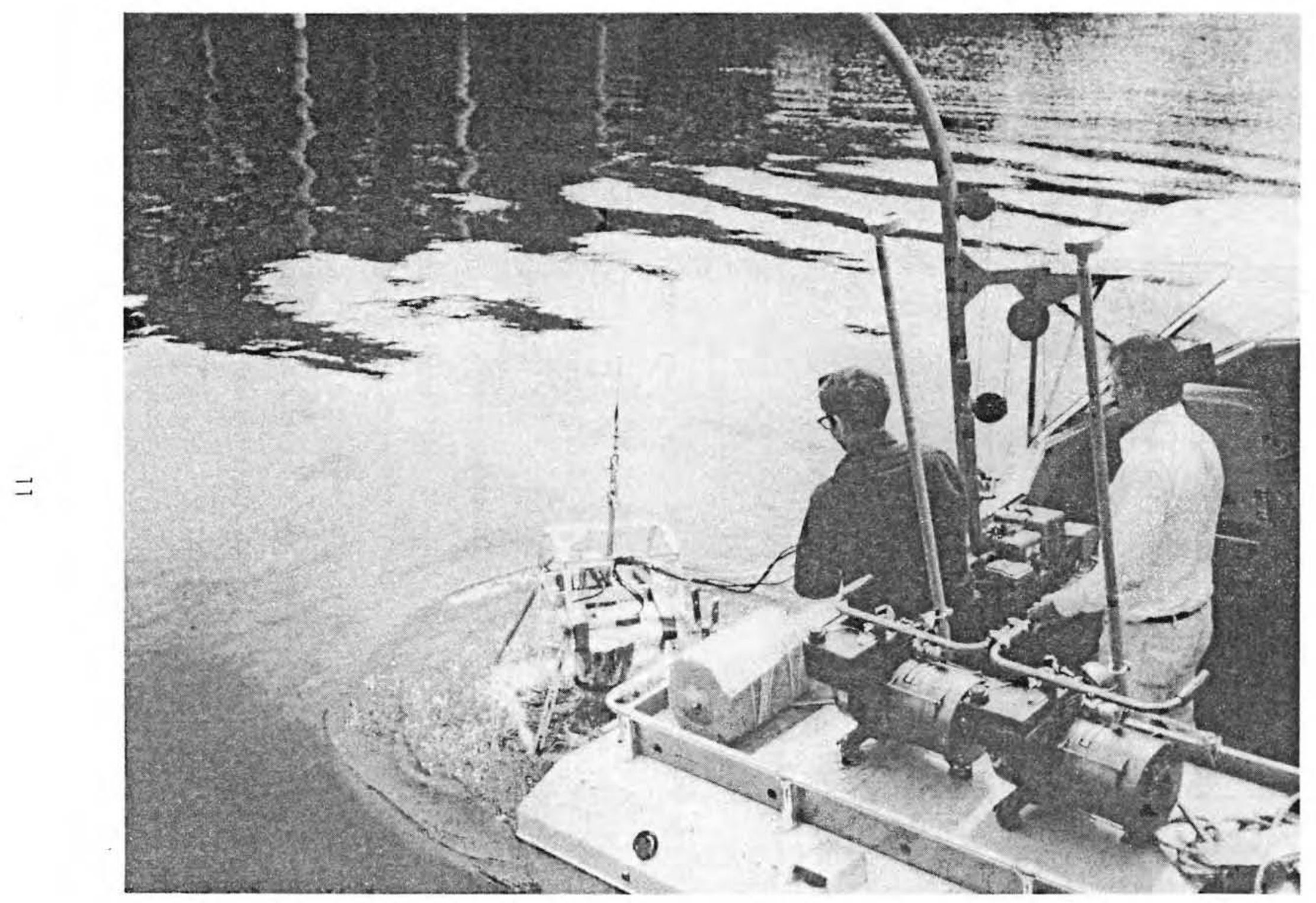

Figure 5. Insitu X-ray fluorescence spectrometer operating from an 8 meter surface vessel 
in hard copy if required. In this fashion, the analyst had immediately availabie the relative concentrations of pollutants such as $\mathrm{Pb}, \mathrm{Hg}, \mathrm{As}, \mathrm{Zn}$, $\mathrm{Ni}, \mathrm{Cu}, \mathrm{Fe}, \mathrm{Mn}, \mathrm{Br}, \mathrm{Rb}$, and $\mathrm{Sr}$. Decisions were then made whether to pursue additional analyses of the immediate area, analyze for a longer time, or whether a different area should be studied. Although this is not the way one would operate in a routine fashion, it was the method chosen for this evaluation within the time and dollar restraints of the present program. (See Reconmendations)

Operation from the surface vessel was accomplished in Lake Union (Figure 6), Lake Washington (Figure 7), and a connecting ship canai (Figure 8) -fresh-water areas of the State of Washington--as well as in Puget Sound (Figures 9 - 10), a marine area located in the State of Washington. In Table 1 are shown the measurement parameters used throughout the evaluation of the insitu spectrometer system for the U. S. Coast Guard. Measurements were started on July 10, 1979, and finished on July 17, 1979. Counting intervals varied from 300 to 6000 seconds. The measurement locations are noted on Figures $6-10$ denoting specific points of analysis in the freshwater areas of Lake Union, Lake Washington and the ship canal, and in the marine areas, Elliott Bay and Point Defiance in Puget Sound. Sample numbers 4, 5, 6, and 7 were standards run during the experimental period. Sample numbers $22,23,24,34,35,36,45$, 51,54 and 59 were analyses of lead sheets or lead standards to insure system operation throughout the experiment.

\section{STANDARDIZATION}

The system was calibrated during the experimental evaluation with thin 


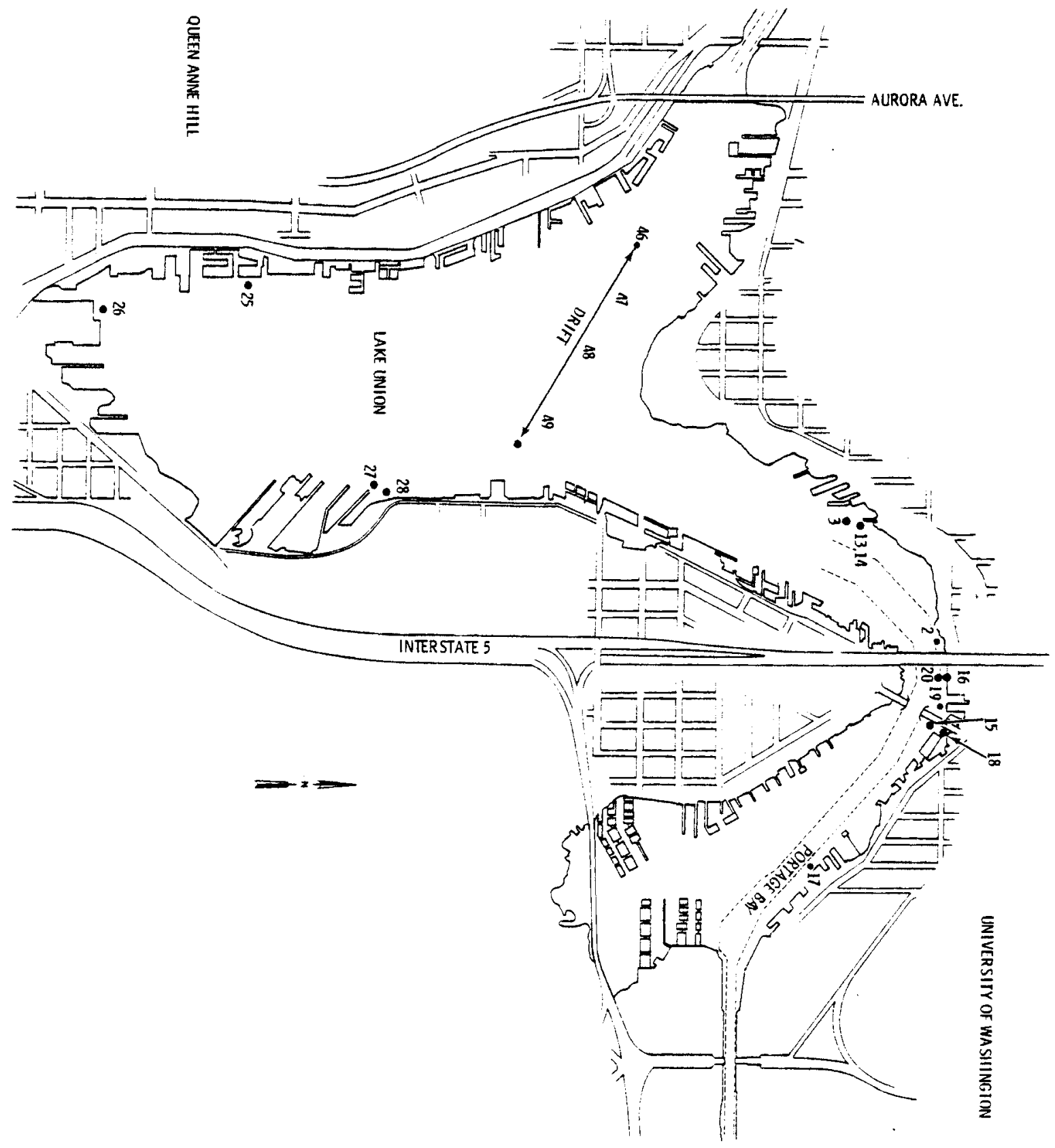

Figure 6 Locations in Lake Union analyzed with in-situ X-ray fluorescence spectrometry for inorganic species. 


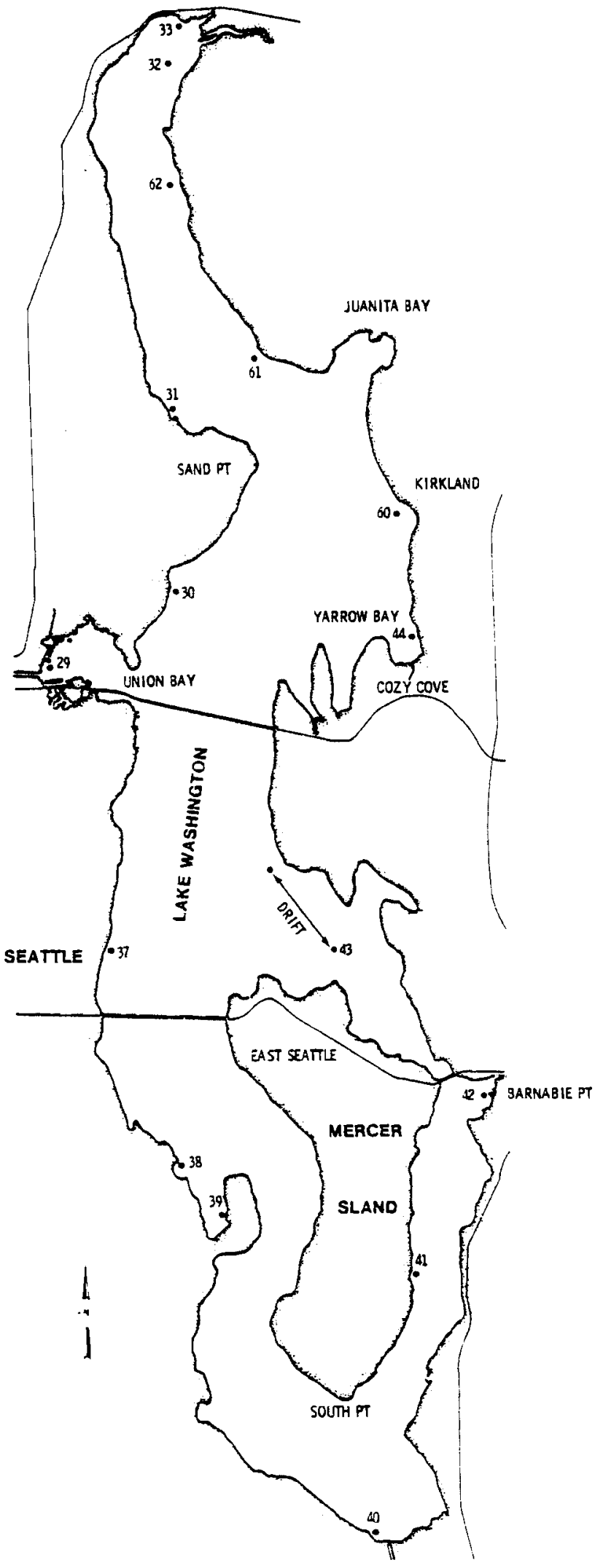

Figure 7 Locations in Lake Washington analyzed with in-situ $X$-ray fluorescence spectrometry for inorganic species. 


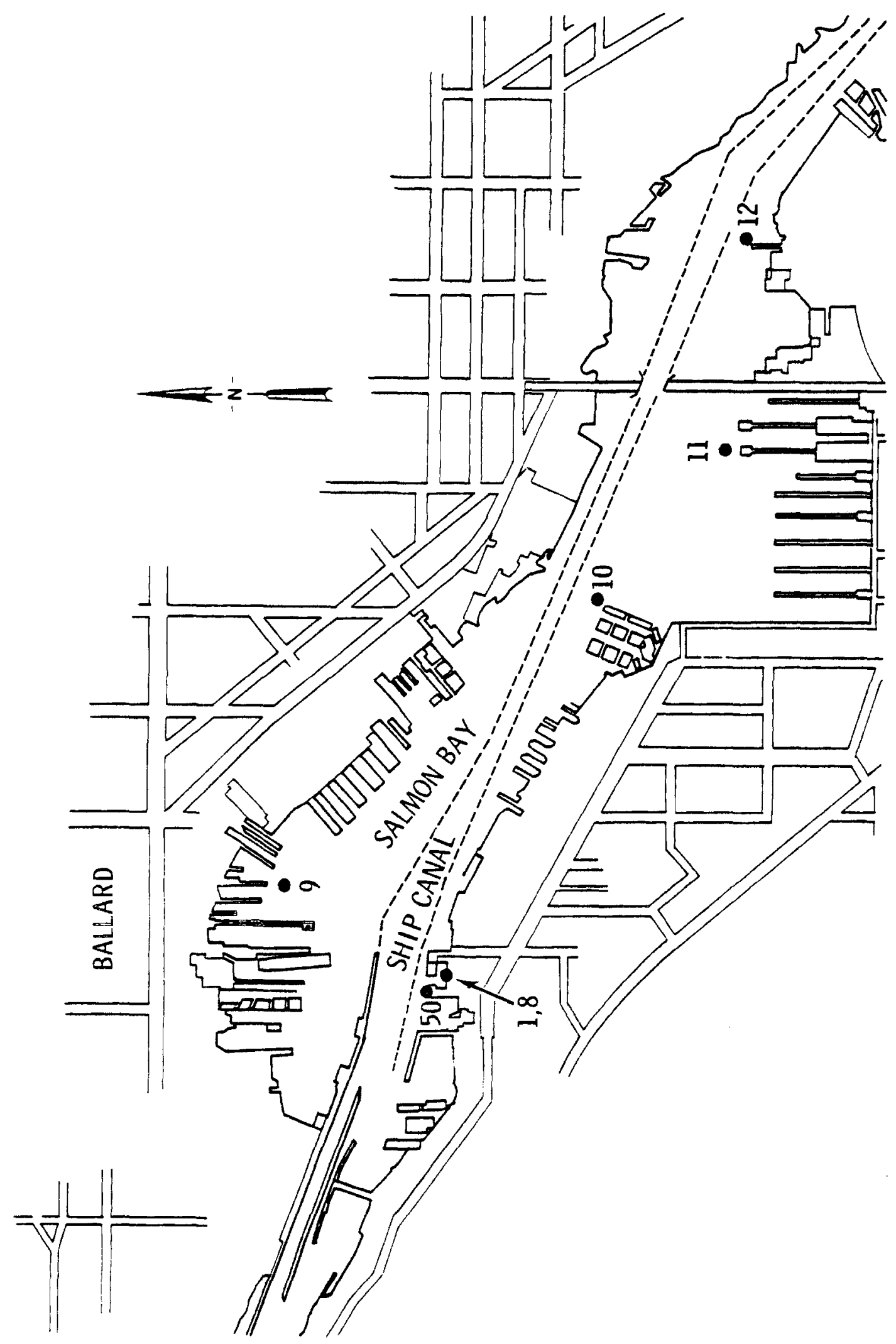

Figure 8 Locations in the Ship Canal analyzed with in-situ X-ray fluorescence spectrometry for inorganic species. 


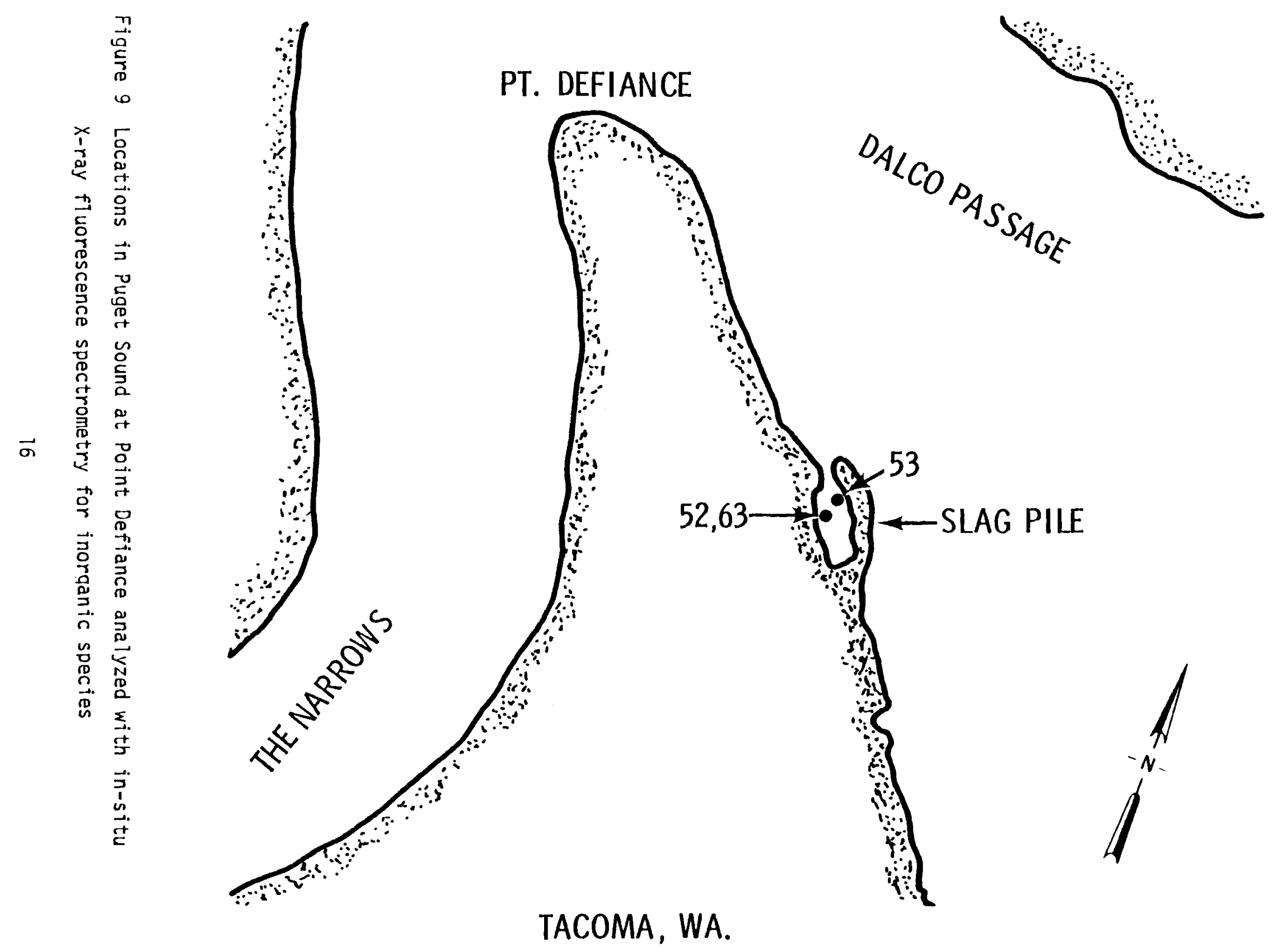




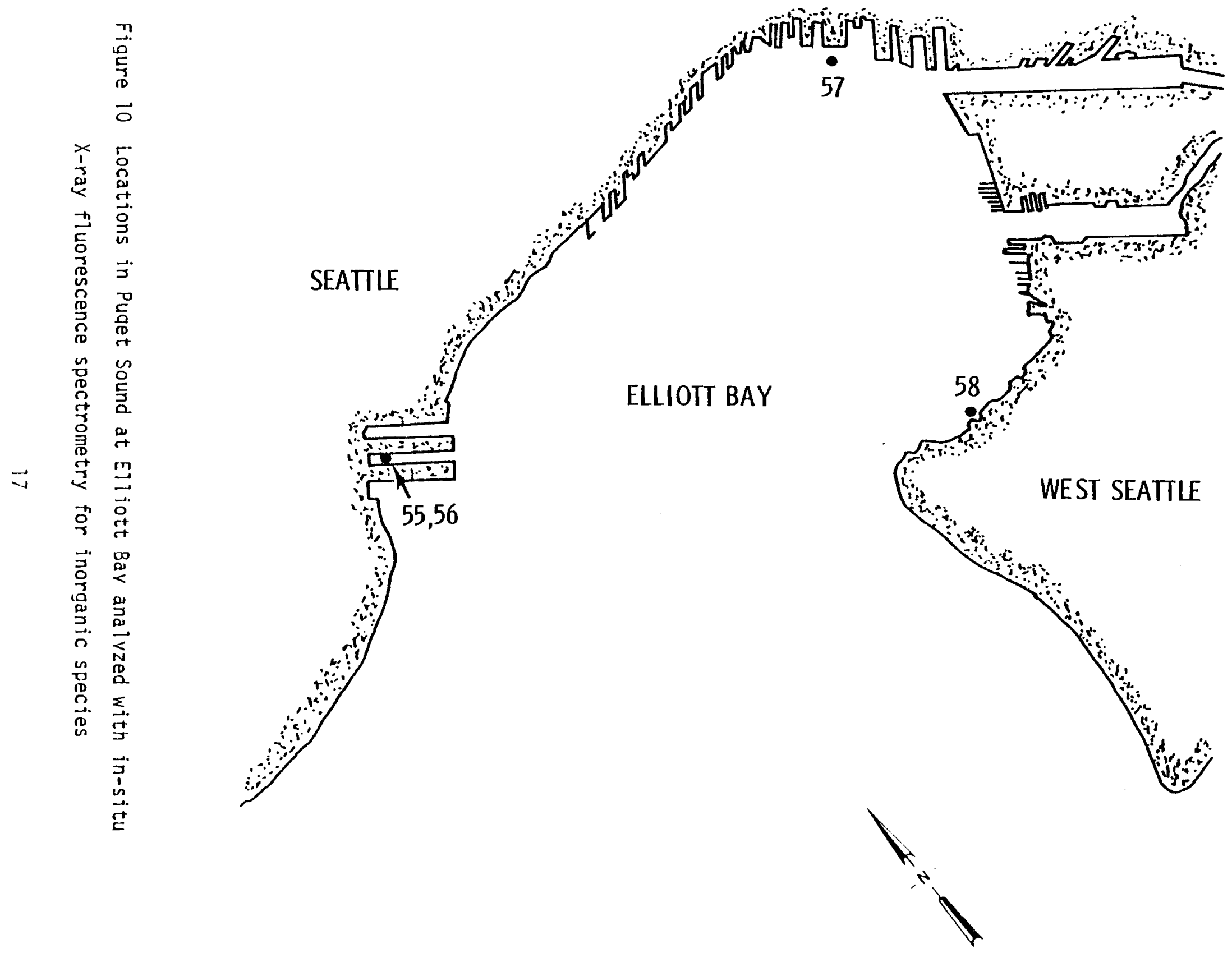


TABLE 1

\section{MEASUREMENT PARAMETERS}

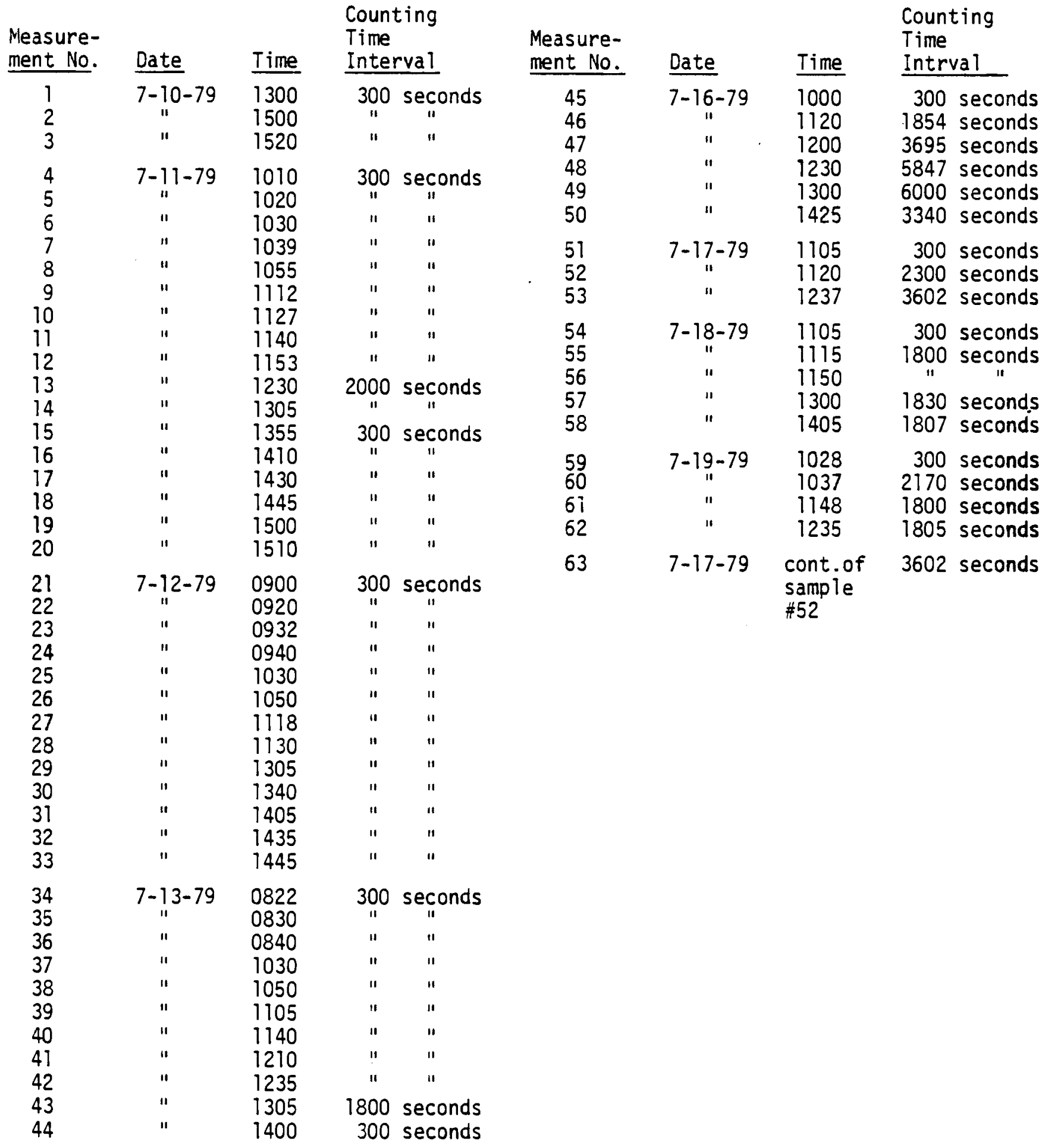


source standards which were backed by synthetic sediment surfaces and with infinitely thick homogeneous standards of $\mathrm{Fe}, \mathrm{Pb}, \mathrm{Zr}$ and As. This method of calibration allows an analysis to be achieved to within $\pm 30 \%$ as will be discussed later.

In Figure 11 is shown the relative counting efficiency as a function of channel number which is proportional to energy and thus to various $x$-rays from specific elements. The elements $\mathrm{Fe}, \mathrm{Cu}, \mathrm{Zn}, \mathrm{Rb}, \mathrm{Sr}$, and $\mathrm{Zr}$ are shown on the relative efficiency curve. The analysis in this case used $109 \mathrm{Cd}$ as a radioisotopic excitation source. Cadmium-109 emits 22.1 and $25 \mathrm{keV}$ photons. Iron is detected most poorly, $\mathrm{Zr}$ the best, with $\mathrm{Cu}, \mathrm{Zn}, \mathrm{Rb}, \mathrm{Sr}$ being intermediate. This happens because ${ }^{109} \mathrm{Cd}$ excitation energy is closest (but exceeds) the energy required to vacate the electron from its shell in the Ir atom. The closer the excitation energy fit to the required energy, the higher the probability of ejecting the electron and producing the $x$-ray of interest. In general, standardization for an X-ray fluorescence spectrometer is accomplished using various thin element or infinitely thick element standards. The data generated by each standard are normally stored in a computer memory and are analyzed by a matrixcorrection program. A matrix correction program for in-situ $X$-ray fluorescence analys is has been developed at Battelle-Northwest using the ratio of the coherent-incoherent scatter peaks to generate the average charge $(Z)$ of the entire matrix material. This in turn is used to correct the spectra which results in a new coherent-incoherent scatter peak ratio. The iteration of this procedure continues until a good repetitive fit is obtained. In this fashion, the entire spectrum is corrected for the amount of low $\mathrm{Z}$ interference $\left(\mathrm{H}_{2} \mathrm{O}\right)$ which modifies the total analysis. 


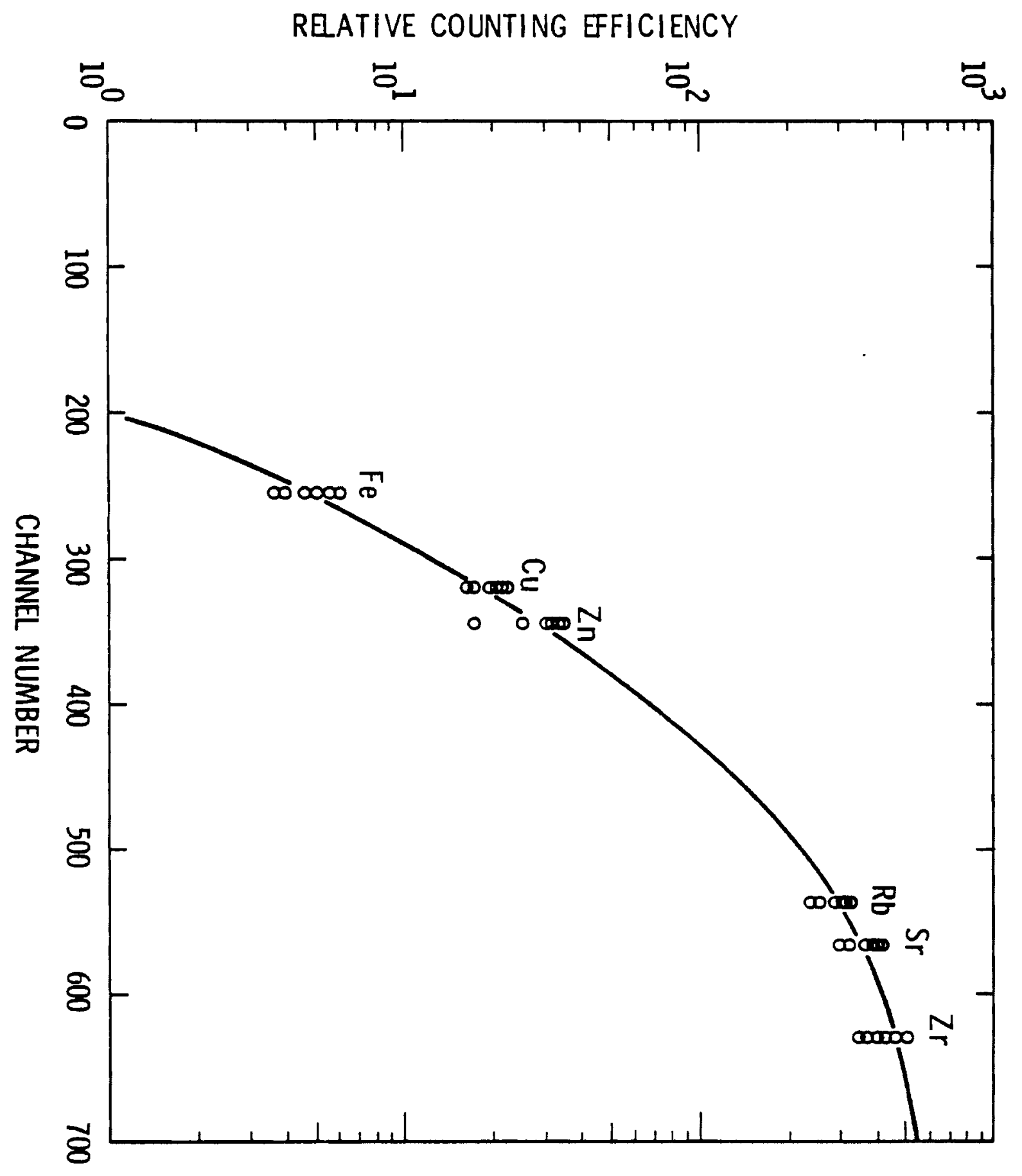

Figure 11 The relative counting efficiency of a Si(Li) detector for photons emitted by $\mathrm{Fe}, \mathrm{Cu}, \mathrm{Zn}, \mathrm{Rb}, \mathrm{Sr}$, and $\mathrm{Zr}$ following ${ }^{109} \mathrm{Cd}$ excitation. 
TABLE 2

DETECTION SENSITIVITIES AND PROMINENT X-RAY ENERGY LINES FOR THE IN SITU SEABED ANALYZER

SENSITIVITY*

PROMINENT X-RAY ENERGIES **

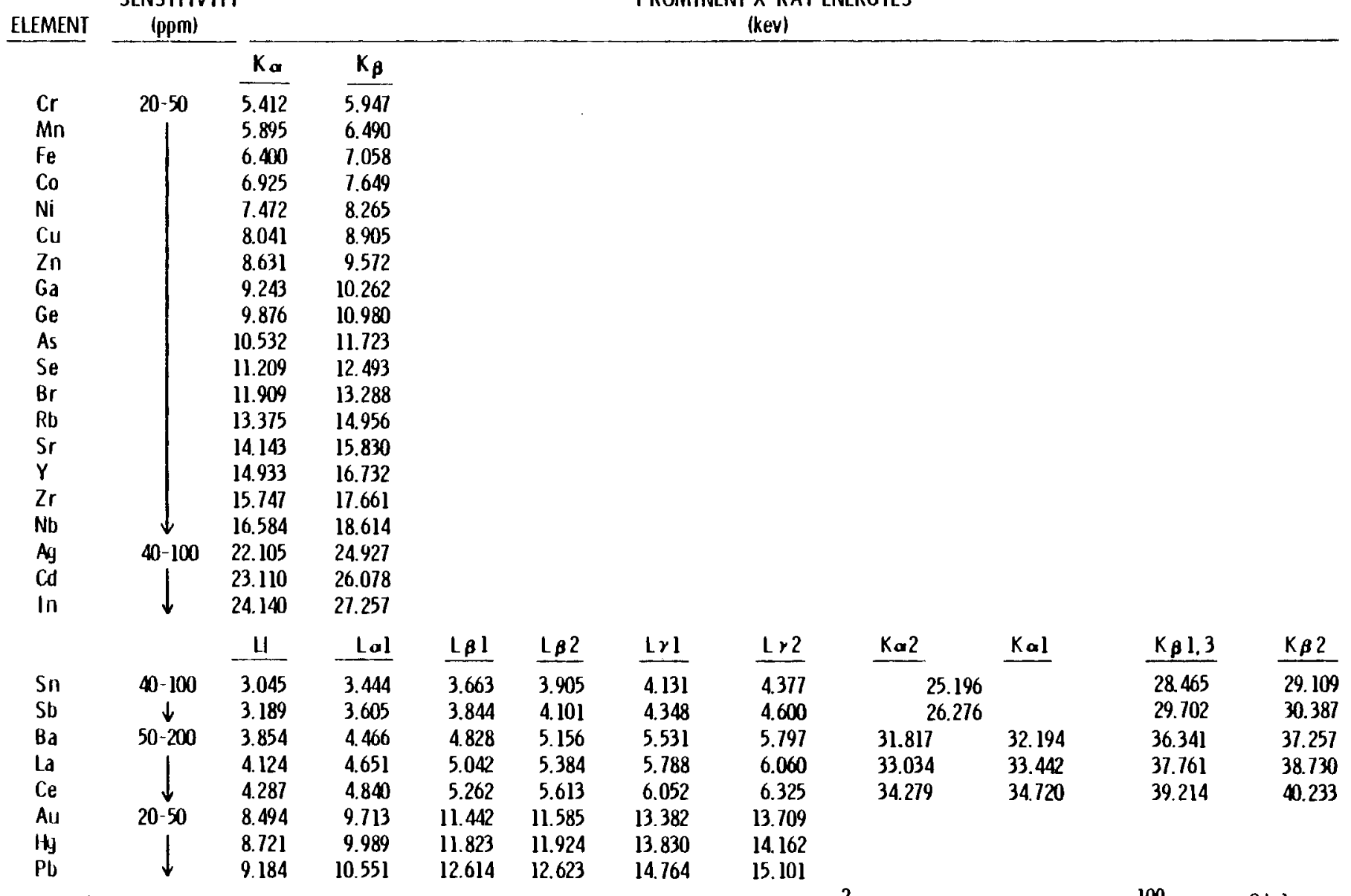

* based on 30 detection limits using a 5 minute analysis an $80 \mathrm{~mm}^{2}$ Si lli) diode and a $100 \mathrm{mc} 109 \mathrm{Ca}$ or 241 Am SOURCE

* * aPPROXIMATE RELATIVE INIENSITY RATIOS WITHIIN SERIES OF A GIVEN ELEMENT ARE $(K a l=100)$ :

$\begin{array}{llll}K \alpha 1=100 & L \alpha 1=100 & L \beta 4=3-5 & M a 1,2=100 \\ K \alpha 2=50 & L \alpha 2=10 & L \gamma \mid=1-10 & M \beta=\sim 60 \\ K \alpha 1,2=150 & L \beta 1=50 & L \gamma 3=0.5-2 & \\ K \beta 1=15-30 & L \beta 2=20 & L I=1-3 & \\ K \beta 2=1-10 & L \beta 3=1-6 & L N=1 & \end{array}$


The method thus utilizes the incoherent and coherent scatter peaks obtained in $X$-ray spectral analysis to estimate the amount of low $Z$ material to be considered in computing the total self-absorption factors. This permits the calibration of the in-situ probe to vary with the large changes in sample matrix which are encountered in underwater analyses. This procedure works well with underwater $X$-ray fluorescence analyses since it allows a correction to be made for varying degrees of water viewed by the detector system.

Table 2 shows the detection sensitivities and prominent $X$-ray energy lines for the in-situ seabed analyzer for a series of elements which would be analyzed using ${ }^{109} \mathrm{Cd}$ and $241 \mathrm{Am}$ radioisotopic sources. The sensitivity in parts per million varies from 20 to $40 \mathrm{ppm}$ based on 3 sigma detection limits using a $5 \mathrm{~min}$ analysis, an $80 \mathrm{~mm}^{2} \mathrm{Si}(\mathrm{Li})$ diode and a $100 \mathrm{mCi}$ radioisotopiC source. The relative intensity ratios within a series for a given element are also listed. Of course, better detection limits can be achieved by not requiring the 3 sigma detection limit.

Table 3 lists the elements and their associated $X$-ray energies used in the present evaluation. Thick sand sources were placed under the spectrometer to simulate the ocean floor. These thick standards consisted of a homogeneously mixed insoluble compound of the element of interest in a known background dunite sand matrix. During the course of the present evaluation the lead standard became nonhomogeneous, but only toward the end of the experiment. A thick lead sheet was used throughout the experiment to verify system operations and to set the gain of the amplifiers to that of the previously analyzed standards. A comparison of the in-situ and laboratory X-ray fluorescence analyzed elemental concentrations obtained from the standards is shown in 
TABLE 3

$X$-RAY ENERGIES AS A FUNCTION OF ELEMENTS

$\begin{array}{lc}\text { NO. ELEMENT } & \text { ENERGY (keV) } \\ \text { 1. } \mathrm{Cl}(\mathrm{K}) & 2.622 \\ \text { 2. } \mathrm{K}(\mathrm{K}) & 3.312 \\ \text { 3. } \mathrm{Ca}(\mathrm{K}) & 3.690 \\ \text { 4. } \mathrm{Ti}(\mathrm{K}) & 4.508 \\ \text { 5. } \mathrm{V}(\mathrm{K}) & 4.949 \\ \text { 6. } \mathrm{Cr}(\mathrm{K}) & 5.411 \\ \text { 7. } \mathrm{Ba}(\mathrm{L}) & 5.531 \\ \text { 8. } \mathrm{Mn}(\mathrm{K}) & 5.895 \\ \text { 9. } \mathrm{Fe}(\mathrm{K}) & 6.400 \\ \text { 10. } \mathrm{Co}(\mathrm{K}) & 6.925 \\ \text { 11. } \mathrm{Ni} \mathrm{(K)} & 7.472 \\ \text { 12. } \mathrm{Cu}(\mathrm{K}) & 8.041 \\ \text { 13. } \mathrm{Zn} \mathrm{(K)} & 8.631 \\ \text { 14. } \mathrm{Ga}(\mathrm{K}) & 9.243 \\ \text { 15. } \mathrm{Hg}(\mathrm{L}) & 9.987 \\ \text { 16. } \mathrm{Se}(\mathrm{K}) & 11.210 \\ \text { 17. } \mathrm{Pb}(\mathrm{L}) & 12.611 \\ \text { 18. } \mathrm{As} \mathrm{(K)} & 10.532 \\ \text { 19. } \mathrm{Br}(\mathrm{K}) & 11.907 \\ \text { 20. } \mathrm{Rb}(\mathrm{K}) & 13.375 \\ \text { 21. } \mathrm{U} \mathrm{(L)} & 13.610 \\ \text { 22. } \mathrm{Sr}(\mathrm{K}) & 14.142 \\ \text { 23. } \mathrm{Y} \mathrm{(K)} & 14.933 \\ \text { 24. } \mathrm{Zr} \mathrm{(K)} & 15.746 \\ \text { 25. } \mathrm{Nb}(\mathrm{K}) & 16.584 \\ \text { 26. } \mathrm{Mo} \mathrm{(K)} & 17.443 \\ \end{array}$


Table 4. The elements $\mathrm{Pb}, \mathrm{As}, \mathrm{Fe}$, and $\mathrm{Zr}$ were analyzed. The data obtained by laboratory analysis in both 1978 and 1979 agreed to within 20\% of that obtained by the in-situ analyzer, except for As which was 3 fold low in 1979. The As standard must thus be made fresh; it separated to a neterogeneous state instead of a nomogeneous state. This was found in the field by analyzing the top and bottom of the standard.

A method devised by Nielson, $\left({ }^{7}\right)$ which has been described and evaluated separately, uses thin and thick sample calibrations in an iterative procedure to obtain the in-situ concentrations of elements in the unknown matrix. Calibration of the $X$-ray scatter peaks is also accomplished in the laboratory using thick-sediment samples whose composition has been previously determined. Even with the modern methods of computer analysis of the spectral data, as well as the use of thin and thick underwater element standards, the accuracy of the in-situ method cannot be considered better than $=30 \%$ as shown by the present and previous data (12). However, the precision of the measurements as defined from 10 analyses of each common standard is $\pm 5 \%$.

TABLE 4

A COMPARISON OF LABORATORY \& IN-SITU STANDARDS

\begin{tabular}{|c|c|c|c|c|c|}
\hline $\begin{array}{c}\text { Sample } \\
\text { No. } \\
\end{array}$ & STD & $\begin{array}{c}\text { In-Situ } \\
6 / 79 \\
\end{array}$ & $\begin{array}{l}\text { Laboratory } \\
6 / 79 \\
\end{array}$ & $\begin{array}{c}\text { In-Situ } \\
6 / 78 \\
\end{array}$ & $\begin{array}{l}\text { Laboratory } \\
6 / 78\end{array}$ \\
\hline 4 & $\mathrm{Fe}$ & $6.5 \%$ & $5.8 \%$ & $7.1 \%$ & $5.8 \%$ \\
\hline 5 & $\mathrm{~Pb}$ & 8200 & 9860 & 10,000 & 10,000 \\
\hline 6 & $\mathrm{Zr}$ & 7900 & 8700 & 8200 & 10,000 \\
\hline 7 & As & 400 & 1200 & 1200 & 1000 \\
\hline
\end{tabular}

*Parts per million unless noted otherwise 


\section{DISCUSSION}

The purpose of this study was to evaluate the in-situ fluorescence spectrometer for its usefulness to U. S. Coast Guard problems requiring a determination of elemental concentrations on sediment surfaces and in water columns. Problems encountered with its use, the accuracy achievable, and system designs were to be considered. Tables 5 through 8 describe the sample locations for the entire experimental period. Inorganic element concentrations for Point Defiance and Elliott Bay, Puget Sound, Washington are shown in Table 9; data for the ship canal in Table 10; data collected in Lake Union in Table 11; and data for Lake Washington in Table 12.

The data indicate that the elements with $Z$ greater than $F e$ are generally well analyzed with the in-situ instrument. The data obtained for elements with $Z$ less than Fe normally have large errors associated with them, which is due to their low energy $X$-rays. Previous studies have shown that al though the $\mathrm{Pb}$ concentrations generally decrease as a function of sediment depth, $\mathrm{Cu}, \mathrm{Zn}, \mathrm{As}, \mathrm{Br}$, and $\mathrm{Rb}$ concentrations are quite variable--they do not seem to have any general concentration trend as a function of sediment depth. Concentration increases have been noted earlier (12) for the elements $C_{0}$, $\mathrm{Sr}, \mathrm{Zr}, \mathrm{Nb}$, and Mo. A general discussion of the present data will be found later in this text. 


\section{TABLE 5}

Sample Location Descriptions

In Lake Union, Seattle, Washington

\begin{tabular}{|c|c|c|c|}
\hline $\begin{array}{c}\text { Identification } \\
\text { Number } \\
\end{array}$ & $\begin{array}{l}\text { Sample } \\
\text { Type }\end{array}$ & $\begin{array}{l}\text { Water Depth } \\
\text { (Feet) } \\
\end{array}$ & $\begin{array}{l}\text { Sample Site } \\
\text { Descriptor }\end{array}$ \\
\hline 25 & Sediment & 42 & $\begin{array}{l}1700 \text { West Lake Orive, } \\
\text { Near Union Buirding }\end{array}$ \\
\hline 26 & Sediment & 23 & $\begin{array}{l}\text { United States Navy } \\
\text { Reserve Dock }\end{array}$ \\
\hline 27 & Sediment & 45 & $\begin{array}{l}\text { National Oceanic And } \\
\text { Atmospheric Administration } \\
\text { Dock }\end{array}$ \\
\hline 28 & Sediment & 45 & $\begin{array}{l}\text { Moved Three Feet From } \\
\text { Sample } 27\end{array}$ \\
\hline 46 & $\mathrm{H}_{2} \mathrm{O}$ & 6 & $\begin{array}{l}\text { Elements Measured In Water } \\
\text { And Suspended Sediment Juring } \\
\text { Drift In Lake Union }\end{array}$ \\
\hline 47 & $\mathrm{H}_{2} \mathrm{O}$ & 6 & Re-analysis of Site 46 \\
\hline 48 & $\mathrm{H}_{2} \mathrm{O}$ & 5 & Re-analysis of Site 46 \\
\hline 49 & $\mathrm{H}_{2} \mathrm{O}$ & 6 & Re-analysis of Site 46 \\
\hline
\end{tabular}




\section{TABLE 6}

Sample Location Description In

The Ship Canal, Seattle, Washington

\begin{tabular}{|c|c|c|c|}
\hline $\begin{array}{c}\begin{array}{c}\text { Identification } \\
\text { Number }\end{array} \\
\end{array}$ & $\begin{array}{l}\text { Sample } \\
\text { Type }\end{array}$ & $\begin{array}{l}\text { Water Depth } \\
\text { (Feet) }\end{array}$ & $\begin{array}{l}\text { Sample Site } \\
\text { Descriptor }\end{array}$ \\
\hline 1 & Sediment & 11 & $\begin{array}{l}\text { United States Coast Guard } \\
\text { North Support Station, East } \\
\text { Of Locks }\end{array}$ \\
\hline 2 & Sediment & 13 & Ivor's Salmon House \\
\hline 3 & Sediment & 19. & $\begin{array}{l}\text { Immediately West of I-5 } \\
\text { Bridge, Gasworks Restaurant }\end{array}$ \\
\hline 8 & Sediment & 8 & $\begin{array}{l}\text { United States Coast Guard } \\
\text { North Support Station }\end{array}$ \\
\hline 9 & Sediment & 20 & $\begin{array}{l}\text { Across Canal From United } \\
\text { States Coast Guard North } \\
\text { Support Station }\end{array}$ \\
\hline 10 & $\mathrm{H}_{2} \mathrm{O}$ & 4 & $\begin{array}{l}\text { Elements Measured in } \mathrm{H}_{2} \mathrm{O} \text { And } \\
\text { Suspended Sediment, Di\&k } \\
\text { Delany's Marine }\end{array}$ \\
\hline 11 & Sediment & 24 & $\begin{array}{l}\text { 1/4 Mile West of Ballard } \\
\text { Bridge, South Side }\end{array}$ \\
\hline 12 & Sedinient & 17 & $\begin{array}{l}\text { 1/4 Mile East of Baliard } \\
\text { Bridge, South Side }\end{array}$ \\
\hline 13 & Sediment & 13 & Gasinorks Restaurant \\
\hline 14 & Sediment & 13 & Re-analysis of Site 13 \\
\hline 15 & Sediment & 14 & $\begin{array}{l}\text { University of Washington } \\
\text { Dockage App? ied Physics Lab, } \\
\text { Between I-5 And Aurora Bridge }\end{array}$ \\
\hline 18 & Sediment & 14 & Re-analysis of Site 15 \\
\hline 16 & Sediment & 23 & $\begin{array}{l}\text { Tolly Craft Cockage. May not } \\
\text { have been in contact with } \\
\text { bottom. }\end{array}$ \\
\hline 19 & Sediment & 23 & Re-analysis of Site 16 \\
\hline 17 & Sediment & 23 & $\begin{array}{l}\text { University of Washington } \\
\text { Oceanography Dock }\end{array}$ \\
\hline 20 & Sedirient & 16 & $\begin{array}{l}\text { Analysis of Area } 100 \text { Feet } \\
\text { Closer To Shore Than Site } 16\end{array}$ \\
\hline 50 & Sediment & 8 & $\begin{array}{l}\text { United States Coast Guard } \\
\text { iorth Support Station }\end{array}$ \\
\hline
\end{tabular}


TABLE 7

Sample Location Descriptions In

Lake Washington, Seattle, Washington

\begin{tabular}{|c|c|c|c|}
\hline $\begin{array}{l}\text { Identification } \\
\text { Number } \\
\end{array}$ & $\begin{array}{l}\text { Sample } \\
\text { Type }\end{array}$ & $\begin{array}{l}\text { Water Depth } \\
\text { (Feet) } \\
\end{array}$ & $\begin{array}{l}\text { Sample Site } \\
\text { Descriptor }\end{array}$ \\
\hline 29 & Sediment & 8 & $\begin{array}{l}\text { Heavy Vegetation, University } \\
\text { of Washington Yacht Dock }\end{array}$ \\
\hline 30 & Sediment & 5 & $\begin{array}{l}\text { Swim Club Dock At Laurel Hurst } \\
\text { West Side of Lake Washington }\end{array}$ \\
\hline 31 & Sediment & 29 & Sandpoint Naval Air Station \\
\hline 32 & Sediment & 19 & Barge At Kenmore \\
\hline 33 & Sediment & 6 & $\begin{array}{l}\text { Kenmore Public Dock, North End } \\
\text { of Lake Washington }\end{array}$ \\
\hline 37 & Sediment & 20 & $\begin{array}{l}\text { Leschi Park, Southwest End of } \\
\text { Lake Washington }\end{array}$ \\
\hline 38 & Sediment & 7 & $\begin{array}{l}\text { Lakewood Public Launch, South- } \\
\text { west End of Lake Washington }\end{array}$ \\
\hline 39 & Sediment & 16 & Andrews Bay, Lake Washington \\
\hline 40 & Sediment & 11 & $\begin{array}{l}\text { Will Rogers Sea Plane Pad, } \\
\text { South End Of Lake Washington }\end{array}$ \\
\hline 41 & Sediment & 11 & $\begin{array}{l}\text { Moose Island Park, Southeast } \\
\text { of Mercer Island }\end{array}$ \\
\hline 42 & Sediment & 12 & $\begin{array}{l}\text { Northwest of Port Shores } \\
\text { Yacht Club, Southeast End of } \\
\text { Lake Washington }\end{array}$ \\
\hline 43 & $\mathrm{H}_{2} \mathrm{O}$ & 6 & $\begin{array}{l}\text { Elements Measured In Water } \\
\text { And Suspended Sediment, During } \\
\text { Orift }\end{array}$ \\
\hline 44 & Sediment & 16 & $\begin{array}{l}\text { Yarrow Bay, East Side of Lake } \\
\text { Washington }\end{array}$ \\
\hline 60 & Sediment & 17 & $\begin{array}{l}\text { Kirkland, Washington, North- } \\
\text { west Of Seaport, East Side } \\
\text { Lake Washington }\end{array}$ \\
\hline 61 & Sediment & 6 & $\begin{array}{l}\text { Champagne Point, East Side } \\
\text { Lake Washington }\end{array}$ \\
\hline 62 & Sediment & 19 & $\begin{array}{l}\text { Oanitou Log Storage Area, North } \\
\text { east End Of Lake Washington }\end{array}$ \\
\hline
\end{tabular}


TABLE 8

Sample Location Descriptions In Puget Sound At Point Defiance and Elliot: Bay, Washington

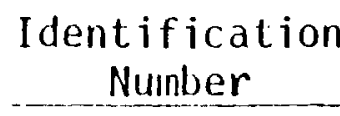

52

63

53

$\approx$

56

57

58

$$
\text { Sample }
$$

Type

Sediment

Location

Point Defiance

Sediment

Point Defiance

Sediment

Point Defiance

Sediment

Ell iot Bay

Elliot Bay

$\mathrm{H}_{2} \mathrm{O}$

Sediment

Elliot Bay

Sediment

Elliot Bay

Water Depth
(Feet)

20

20

37

43

30

17

9
Sample Site Descriptor

East Side, Yacht Basin

Re-analysis of Sample Site 52

Near Slag Pile, Yacht Basin

Boeing Dock, Pier 91

Elements Measured In Water And Suspended Sediment

Washington Street Moorage

Armeni Boat I.aunch, West Seattle Shore 
Table 9. The concentrations of 23 elements in surficial sediments in Puget Sound as determined by in-situ $x$-ray fluorescence spectrometry.

\begin{tabular}{|c|c|c|c|c|c|c|c|c|c|c|c|c|c|c|c|c|c|c|c|c|c|c|c|}
\hline | temlth ler & $c^{x}$ & $r^{t}$ & $\stackrel{x}{v}$ & $c_{r}^{*}$ & MII $^{\mathbf{x}}$ & $\begin{array}{l}x \\
f_{0}^{2}\end{array}$ & $c_{0}^{x}$ & mpn & $\begin{array}{l}\text { Ppü } \\
\text { Cu }\end{array}$ & $\begin{array}{c}\text { ppan } \\
2 n\end{array}$ & $\begin{array}{l}\text { ppon } \\
\text { Gá }\end{array}$ & $\begin{array}{r}\text { ppon } \\
\text { III }\end{array}$ & $\begin{array}{l}\text { pewu } \\
\text { Se }\end{array}$ & PIn: & $\begin{array}{l}\text { ppout } \\
\text { As }\end{array}$ & $\begin{array}{r}\mathrm{ppm} \\
\mathrm{Br}\end{array}$ & $\begin{array}{c}\text { Ppit } \\
\text { RPD }\end{array}$ & $\begin{array}{r}P(M) \\
U \\
\end{array}$ & $\begin{array}{r}\mathrm{m} m \mathrm{sm} \\
\mathrm{s}\end{array}$ & $\begin{array}{r}p \times \times n \\
Y\end{array}$ & $\begin{array}{c}\text { prun } \\
\angle \mathrm{L}\end{array}$ & 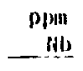 & $\begin{array}{c}\text { PMin } \\
\text { Mu }\end{array}$ \\
\hline 12 & 1.4 & .32 & $<.1 \theta$ & 8.100 & $<.08$ & 10.00 & $<.08$ & $<340$ & 2900 & 1800 & $<120$ & $<320$ & 440 & 760 & 720 & 280 & 50 & $<70$ & 700 & $<20$ & 200 & 10 & 30 \\
\hline 63 & 1.1 & .41 & $<.13$ & $<.08$ & .093 & 9.2 & .089 & $<260$ & 2800 & 1800 & $<90$ & $<260$ & $<30$ & 720 & 700 & 270 & 50 & $<50$ & 660 & .20 & 190 & 9.7 & 20 \\
\hline 13 & .91 & .42 & $<.17$ & $<.10$ & .11 & 11.00 & $<.08$ & $<330$ & 3500 & 1000 & $<120$ & $<290$ & $<40$ & 1500 & 1500 & 600 & 70 & $<70$ & 750 & $<20$ & 250 & $<10$ & 50 \\
\hline Sי & $<.82$ & .74 & $<.18$ & $<.11$ & $<.08$ & 5.4 & $<.07$ & $\angle A 10$ & 300 & 1900 & $<120$ & $<270$ & $<40$ & 4900 & 460 & $<140$ & $<300$ & $<50$ & 420 & $<30$ & 40 & $<10$ & $<10$ \\
\hline 56 & x. 3 & $<.41$ & $<.22$ & $<.16$ & $<.09$ & .10 & 6.01 & $: 310$ & 4300 & $<160$ & $<110$ & $\times 330$ & $<50$ & 90 & $<70$ & 530 & $<26.0$ & $<50$ & 40 & $<10$ & $<10$ & $<10$ & $<20$ \\
\hline 3 & 1.5 & $<.33$ & $<.19$ & $<.12$ & $<890$ & 3.0 & .09 & 1200 & $<250$ & 870 & 400 & 1700 & 100 & 900 & $<120$ & $<70$ & 50 & $<80$ & 270 & 30 & 130 & $<20$ & $<20$ \\
\hline 5 & $<1.5$ & $<.56$ & $<.28$ & $<.22$ & $<.15$ & 4.20 & $\therefore .06$ & $<430$ & 620 & 1100 & 590 & 1900 & 480 & 720 & 4110 & 80 & 180 & 410 & 100 & $<30$ & $<20$ & $<20$ & 30 \\
\hline
\end{tabular}


Table 10. The concentrations of 23 elements in surficial sedinents in the Ship Canal as determined by in-situ $X$-ray fluorescence spectrometry.

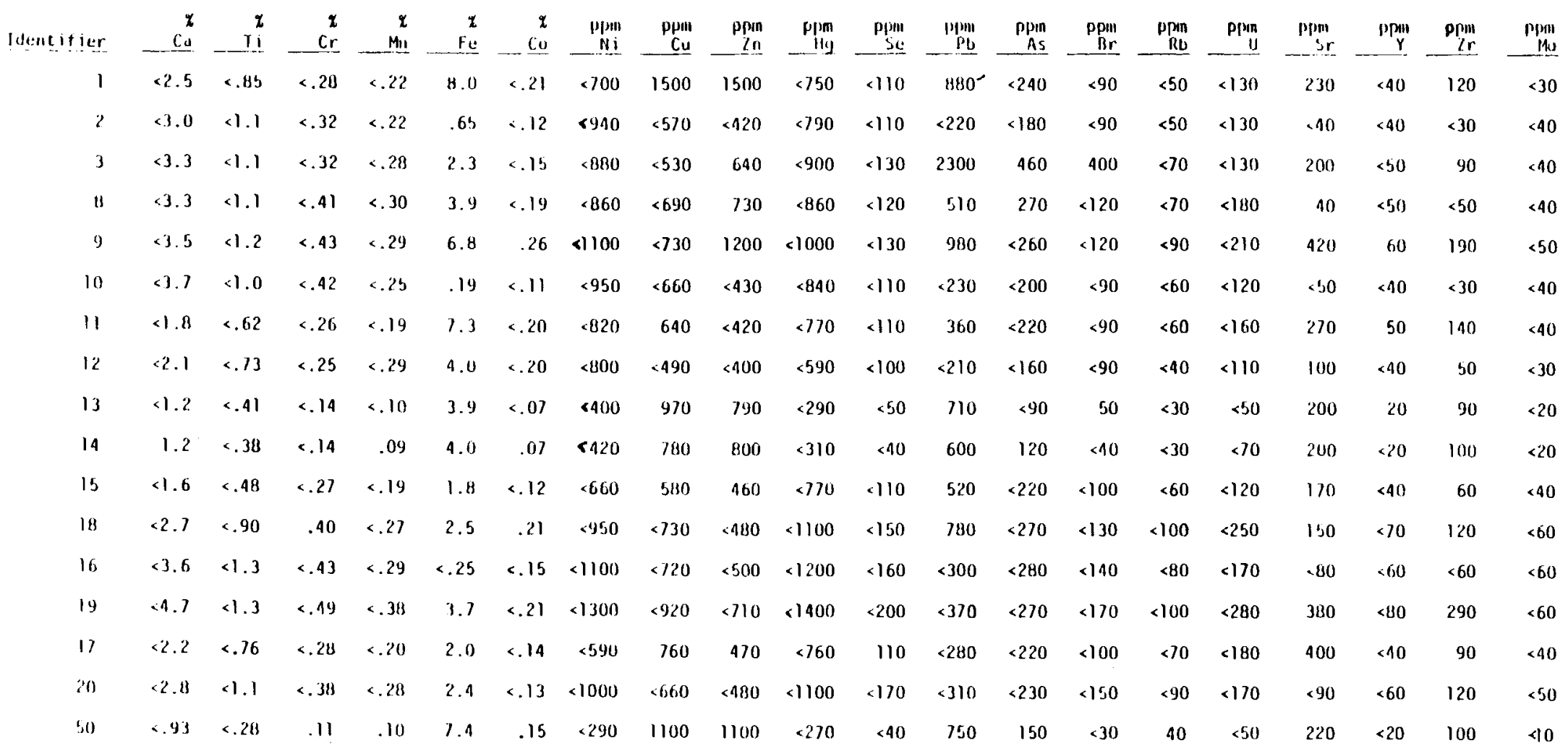


Table 11. The concentrations of 23 elements in surficial sediments in Lake Union as determined by in-situ $x$-ray fluorescence spectronietry.

\begin{tabular}{|c|c|c|c|c|c|c|c|c|c|c|c|c|c|c|c|c|c|c|c|c|c|c|c|}
\hline Identifier & $\begin{array}{r}x \\
\text { ca. } \\
\end{array}$ & -1 & $\begin{array}{r}x \\
y \\
\end{array}$ & $c^{z}$ & $M_{\text {MI }}^{2}$ & $\begin{array}{r}z \\
-r e\end{array}$ & $\begin{array}{r}z \\
- \\
\end{array}$ & $\begin{array}{c}\text { ppun } \\
\text { Ni }\end{array}$ & 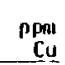 & $\begin{array}{r}p p w a n \\
7 n\end{array}$ & $\begin{array}{c}\text { Ppon } \\
\text { Gad }\end{array}$ & 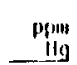 & $\begin{array}{r}\text { ppon } \\
\text { Se } \\
\end{array}$ & Ppou & $\stackrel{p m s}{A s}$ & ${ }_{B r}^{P \mu m}$ & 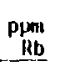 & $\begin{array}{r}\mathrm{npN} \\
\mathbf{1}\end{array}$ & ${ }_{S r}$ & $\underset{Y}{\mathrm{Ppan}}$ & pront & ${ }_{N b}^{P(m+1)}$ & 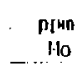 \\
\hline 25 & $<2.8$ & cl. 2 & $<.64$ & $<.36$ & $<.26$ & 3.6 & $<.19$ & <910 & 790 & 930 & $<370$ & $<950$ & $<130$ & BAO & $<280$ & 120 & $c 70$ & $\angle 180$ & 150 & $<60$ & $<50$ & 410 & $<40$ \\
\hline 26 & $<3.6$ & $<1.1$ & $<.74$ & $<.47$ & $<.33$ & 6.6 & $<.28$ & \&1100 & $<880$ & 1100 & $<400$ & $<1200$ & $<160$ & 1000 & $<320$ & $\$ 30$ & $<90$ & $<220$ & 700 & $<60$ & 200 & $\therefore 0$ & $\times 50$ \\
\hline $2 B$ & $<1.9$ & $<.63$ & $<.36$ & .41 & $<.20$ & 3.4 & $<.14$ & \&1100 & $<540$ & 1300 & $<220$ & $<670$ & < 100 & 510 & 330 & $<100$ & $<50$ & $<100$ & 130 & $<40$ & $<10$ & $<311$ & $<10$ \\
\hline 16 & $<1.2$ & $<.39$ & $<.23$ & $<.14$ & $<.09$ & $<.07$ & $<.04$ & $<350$ & $<210$ & $<150$ & $<100$ & $<310$ & $<10$ & $<70$ & $<70$ & $<30$ & $<20$ & $<40$ & $<20$ & $<10$ & $<13.0$ & (10) & .20 \\
\hline 17 & $<.91$ & $<.28$ & $<.16$ & $<.10$ & $<.07$ & .083 & $<.03$ & $<250$ & $<150$ & 150 & .70 & $<200$ & $<30$ & .60 & $<50$ & $<30$ & $<10$ & .30 & 10 & $<10$ & $<10$ & 99.0 & -11.0 \\
\hline 48 & $<.67$ & $<.22$ & $<.14$ & $<.08$ & $<.05$ & .074 & $<.02$ & $<280$ & 160 & $120^{\circ}$ & $<60$ & 180 & $<20$ & $<40$ & $<40$ & $<20$ & 10 & $<20$ & $<10$ & $<7,0$ & $<10$ & $<10$ & $<10$ \\
\hline 19 & $<.66$ & $<.21$ & $<.13$ & $\therefore .08$ & $<.05$ & .075 & $<.02$ & $<290$ & 160 & 120 & $<60$ & $<170$ & $<20$ & $<40$ & $<40$ & -20 & $<10$ & $<20$ & $<10$ & $<7.0$ & $<10$ & $<10$ & $<10$ \\
\hline
\end{tabular}


Table 12. The concentrations of 23 elements in surficial sediments in Lake Washington as determined by in-situ $X$-ray fluorescence spectrometry.

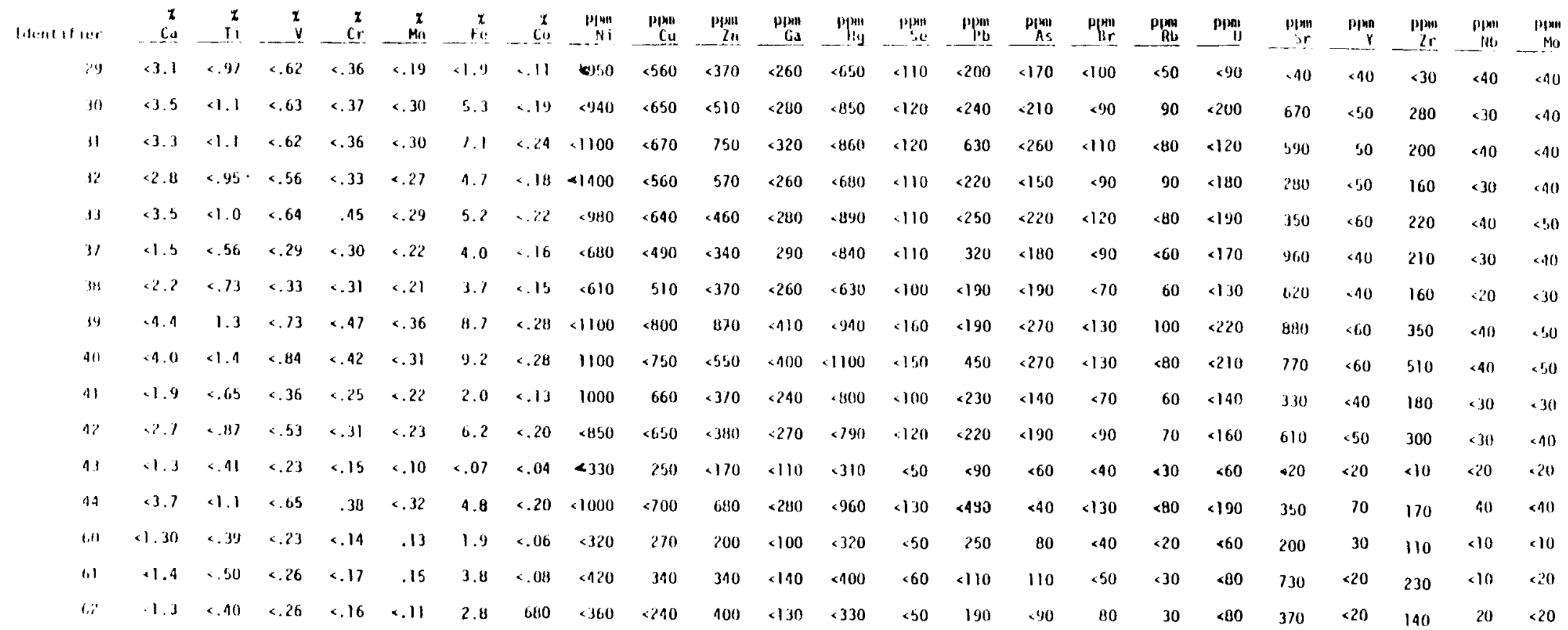


Spectra were drawn for only six of the 60 locations which were analyzed; these figures illustrate the type of spectra obtained with the in-situ spectrometer system.

Figures 12 - 17 show respectively in-situ $X$-ray fluorescence spectra for sample site 3 (ship canal), site 26 (Lake Union), sites 52 and 53 (Point Defiance, Puget Sound), and sites 55 and 57 (Elliott Bay, Puget Sound). These figures show typical spectra obtained from the evaluation experiment. As can be seen, the coherent-incoherent scatter peaks are well defined allowing computer analysis to define the major low $Z$ elements involved in the scattering process. The computer, in the iterative process, also takes into account the actual elemental concentrations after it has identified them.

Figures 14 - 15 illustrate the concentrations of $\mathrm{Pb}$ and As which are relatively constant in this region. The $\mathrm{As}$ and $\mathrm{Pb}$ concentrations are 2-fold greater at location 53 than at location 52 going from an average 750 ppm to $1500 \mathrm{ppm}$, yet the $\mathrm{Fe}$ concentrations at the two sites remain about $10.5 \%$. In other words, the Fe concentrations indicate that the bulk matrix did not change, yet the Pb-As concentrations are 2-fold variant. Since this area is a tailing pile from a smelter, the data seem to indicate that a variable degree of extraction of $\mathrm{Pb}$ and $\mathrm{As}$ from the original ore had been accomplished prior to dumping at these two sites. Copper concentrations were quite uniform from 2900 to $3500 \mathrm{ppm}$. Zinc varied from 1800 to $4000 \mathrm{ppm}$. A seawater environment is indicated by $\mathrm{Br}$ and $\mathrm{Sr}$ concentrations. However, since $B r$ varied 2 -fold in this area it must be bound in the slag material as a chemical compound rather than being simply bromide ions from the seawater environment. Strontium and $\mathrm{Zr}$ were relatively constant in the order of $700 \mathrm{ppm}$ and 


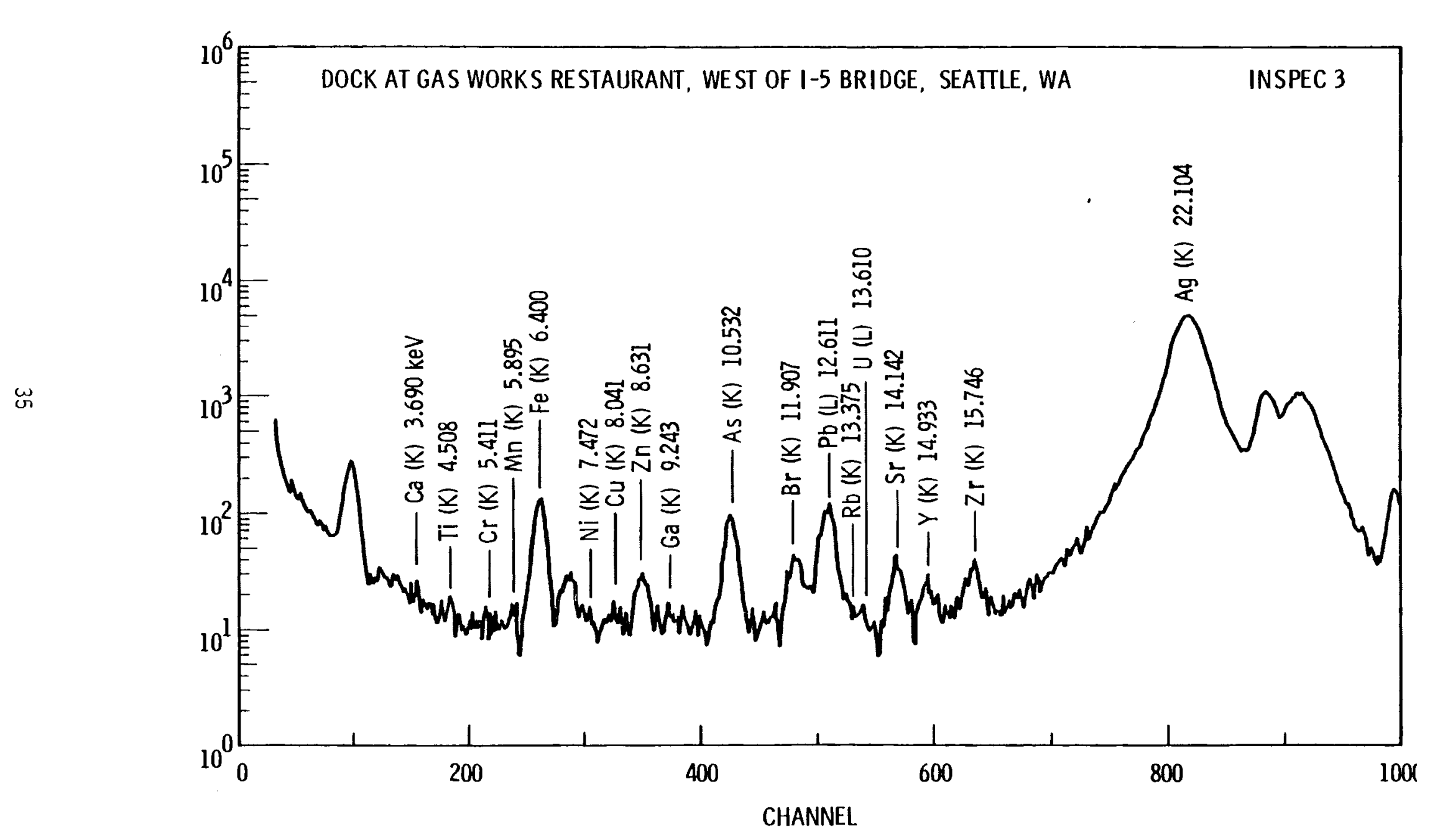

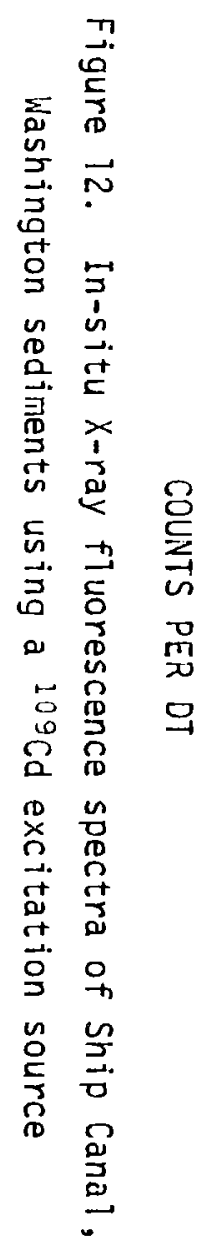




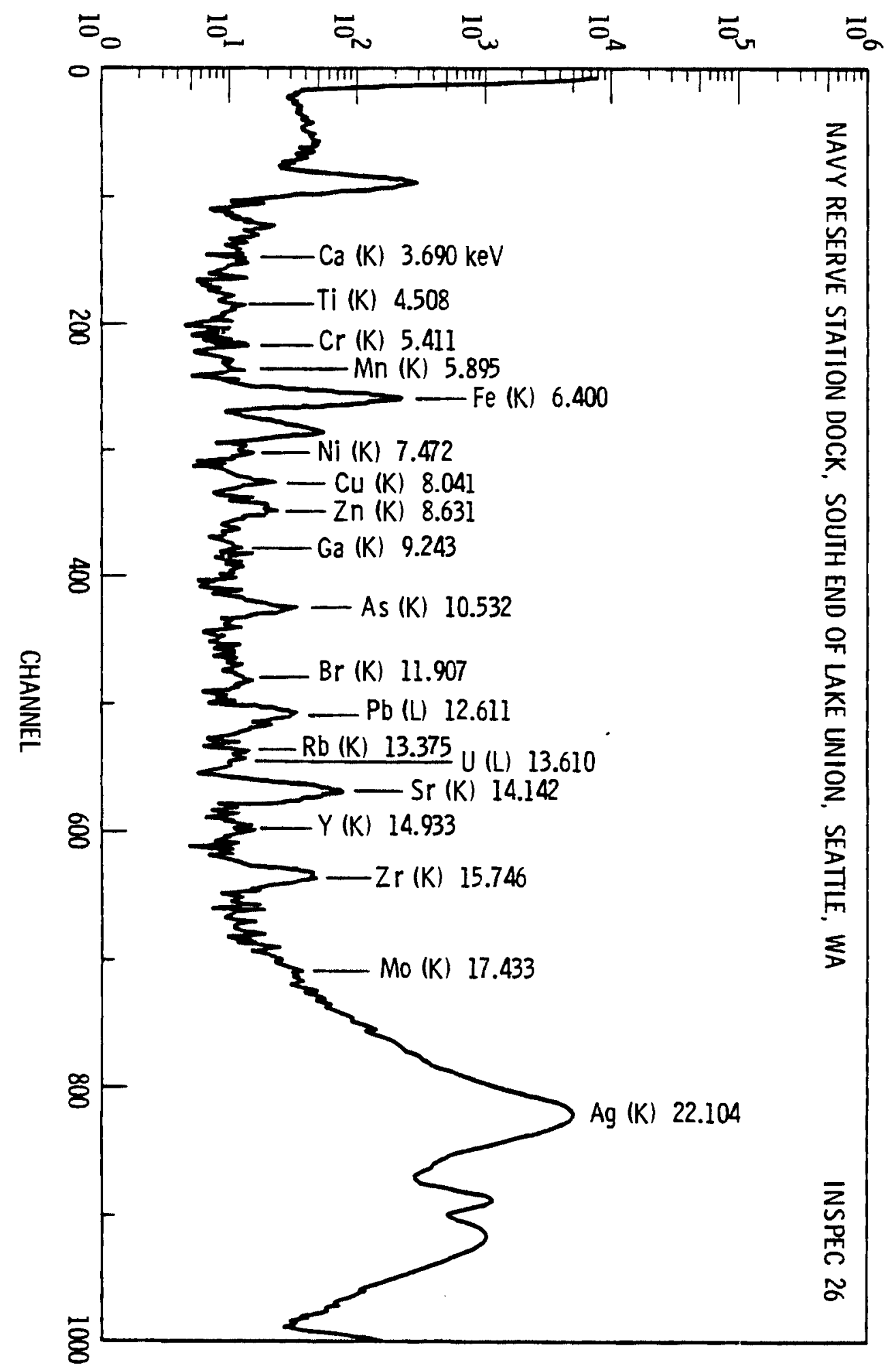

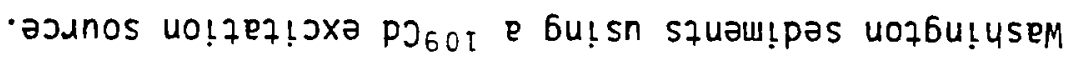

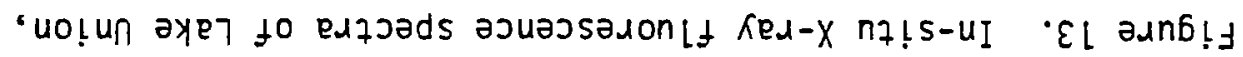




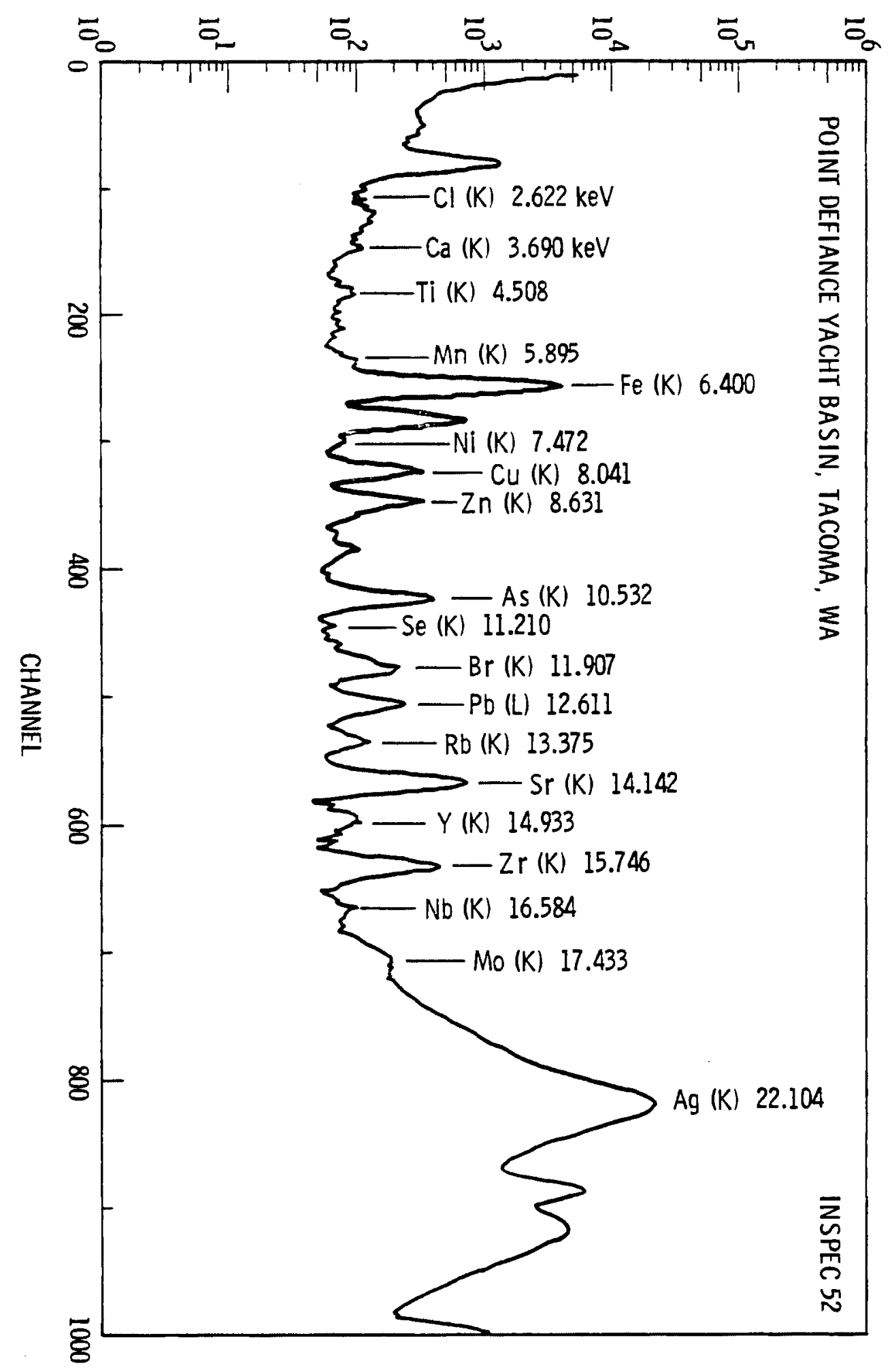

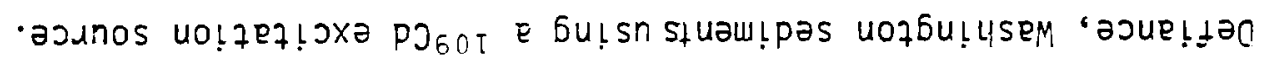
qu!Od to exzoads asuassajon lf ked-X nq!S-UI tol aגnb!f 10 yad SLNnOJ 


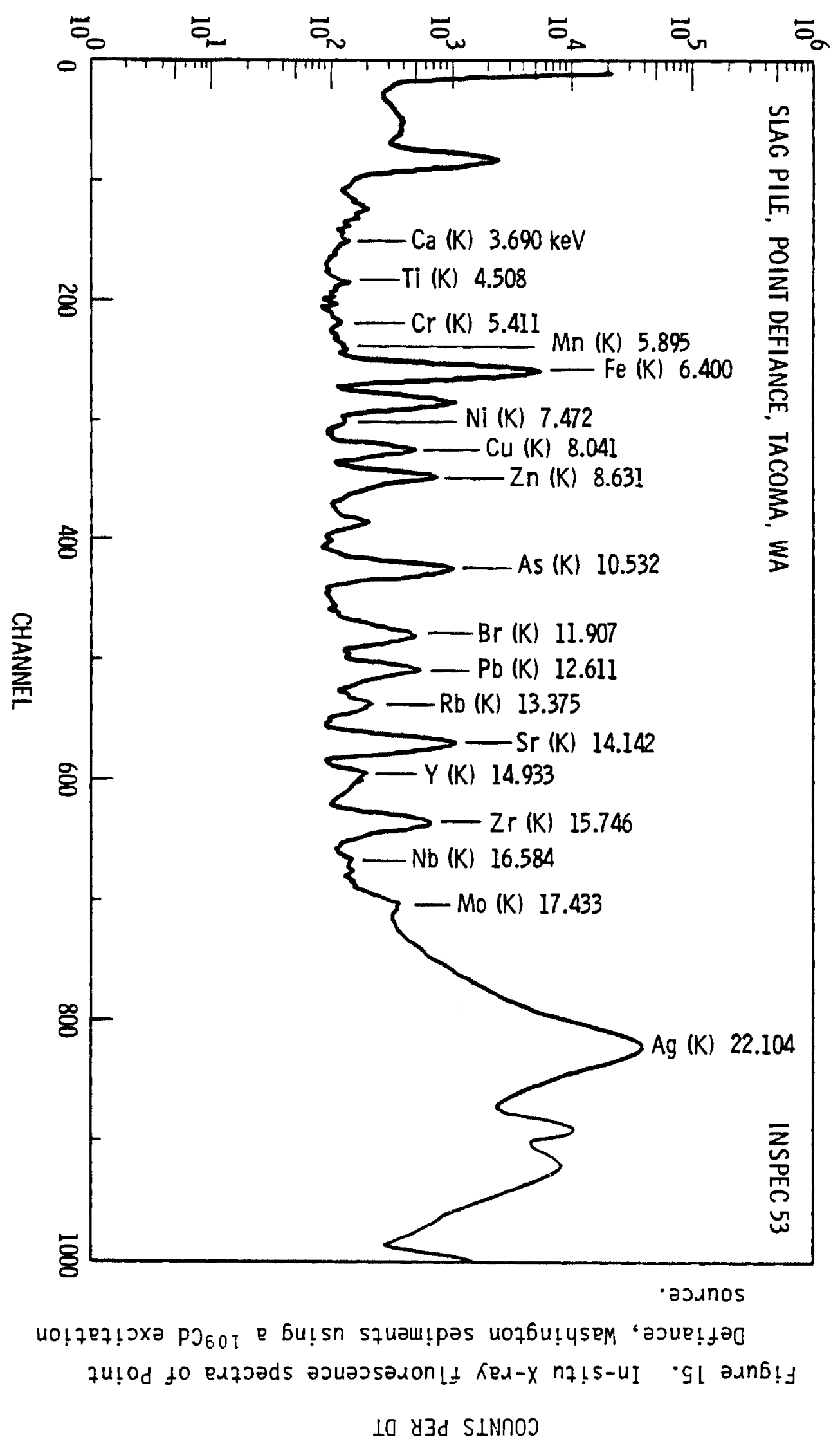




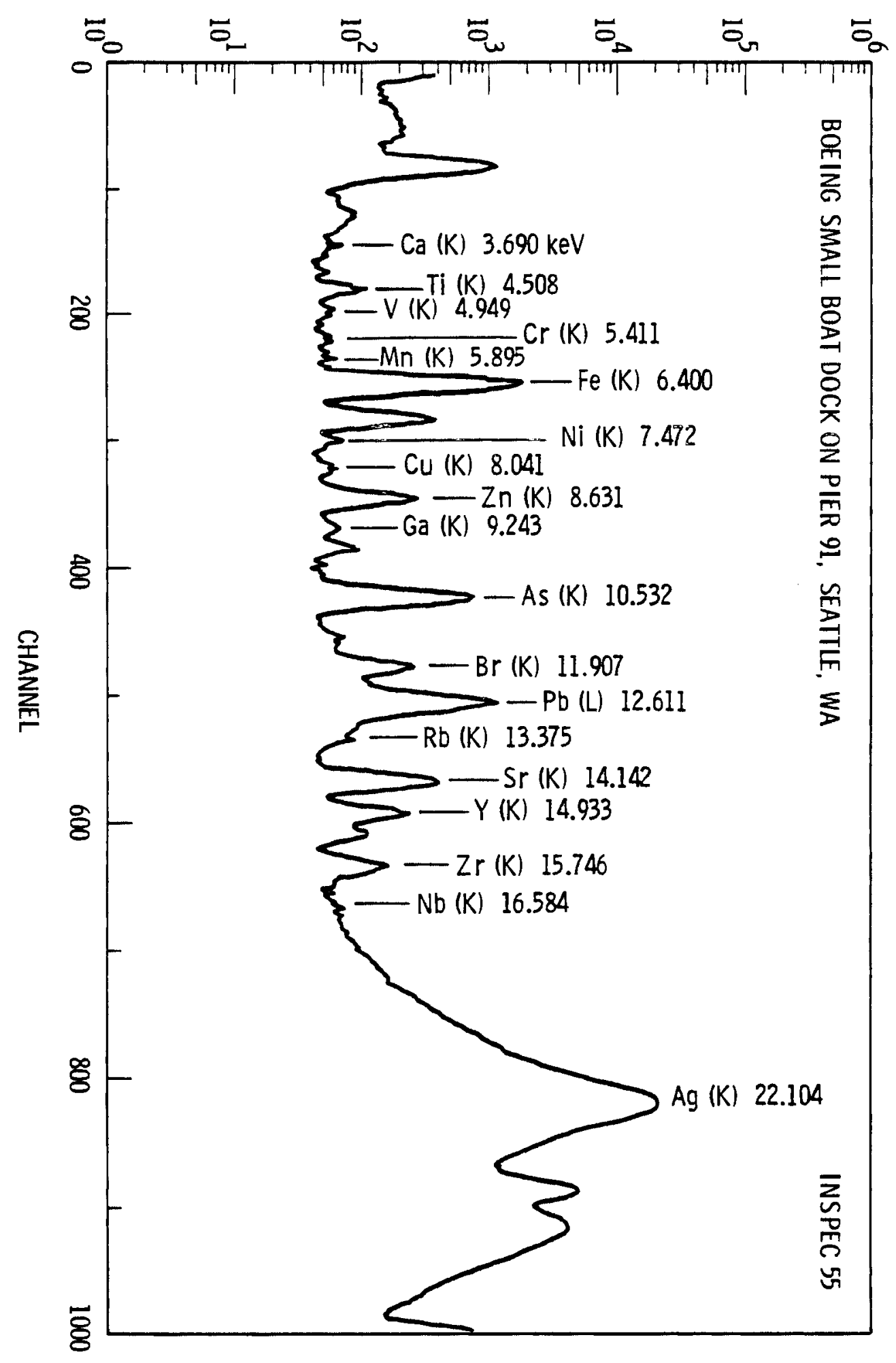

- əsunos uo!zeq!oxa PJ601 e Gu!sn squəm!pəs uoz6u!4seM

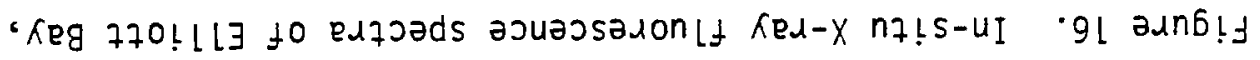
10 yad SINnOJ 

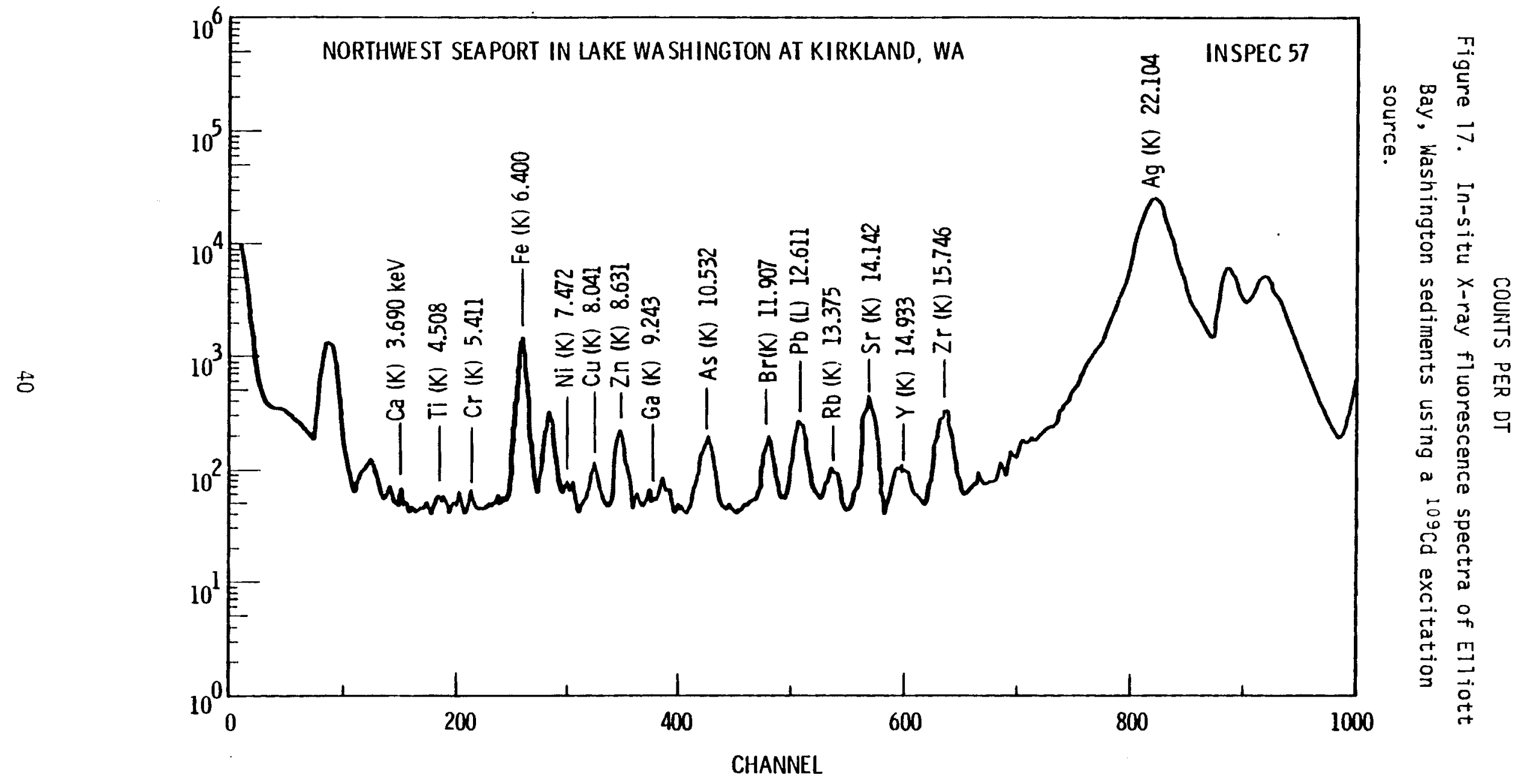


\section{FIGURE 18}

III SITU X-RAY FLUORESCENCE SPECTRA OF

SHIP CANAL SEDIMENTS, WASHINGTON USING ${ }^{109}$ CD AS TIIE EXCITATION SOURCE

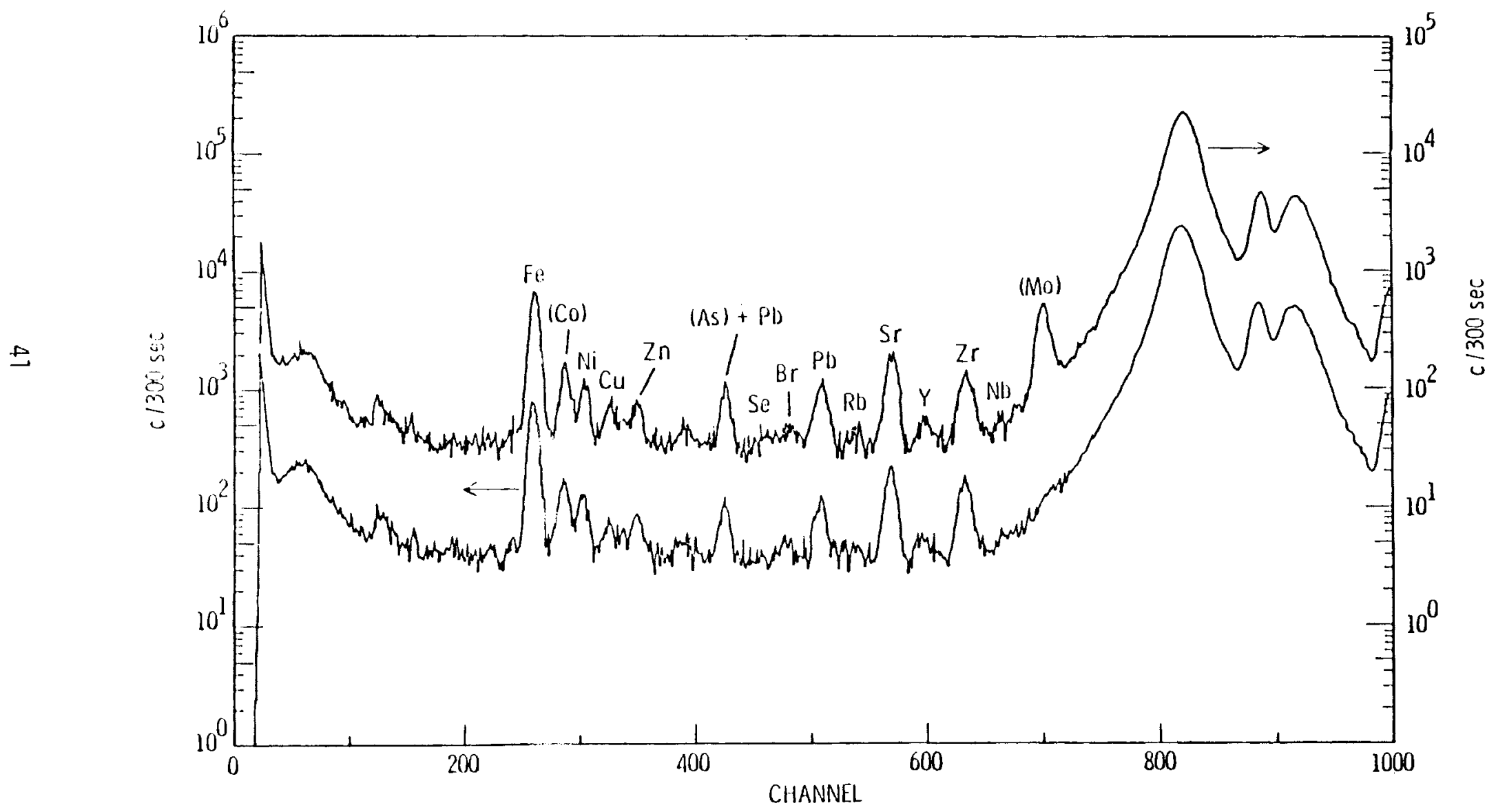


$200 \mathrm{ppm}$, respectively. These samples can be compared to the data obtained at sites 55 and 57 which were sediments located in Elliott Bay, Puget Sound at Pier 91 and the Washington Street moorage. (Figures 16 - 17) In these sediments the Mo is less than $20 \mathrm{ppm}$. The $\mathrm{Sr}$ and $\mathrm{Zr}$ concentrations in the sediment are less than half of that seen in the slag material near Point Defiance. No As was detected; however, high concentrations of $\mathrm{Pb}$ were detected at locations 55 (4900 ppm) while 900 ppm Pb were detected at site 57 . Site 55 is near a dock which has an exceedingly large surface area and drains to the sea; thus, the Pb probably arises from automobile exhausts. The area at sampling site 57 is a cleaner environment with respect to $\mathrm{Pb}$. The $\mathrm{Fe}$ is only 3 to $5 \%$, about half of that seen in the slag material near Point Defiance. Sample 56, a water analysis, illustrates the colloidal or suspended Fe concentrations detected by the spectrometer. This $\mathrm{Fe}$ is in the seawater flocculent material and is only $0.1 \%$ of the sample being viewed by the system. Sample 58 which contains less than $0.20 \% \mathrm{Fe}$ shows that the system was either analyzing low $Z$ material, leaves, etc. at the Armenii boat launch or that it was not sitting on the bottom sediment. It may have been lifted by a rock off the ocean floor such that it was not seeing sediment but was seeing an aqueous sample. In this latter case the $\mathrm{Fe}$ concentration was less than $0.2 \%$; however, the $\mathrm{Cu}, \mathrm{Zn}$, and $\mathrm{Hg}$ values were quite high which is indicative of paper material, possibly a photographic film pack being selectively analyzed by the underwater analyzer. Figure 12 and Table 6 show data from sampling site 3, an area immediately west of the I-5 bridge near the Gasworks restaurant in the ship canal, Seattle, Washington. This sample was chosen because it illustrates typical Fe concentrations in this vicinity (2.3\%). 
Lead concentrations similar to the measured $2300 \mathrm{ppm}$ have been seen in past studies (12) of the area and are generally due to $\mathrm{Pb}$ being washed from the streets of the I-5 bridge area into the ship canal. The Br has not been detected at this concentration in the past. (12) Generally it is much lower. It would thus seem that some material containing $\mathrm{Br}$ has been dumped in this area increasing its concentration. Figure 13 and Table 5 show data taken at location 26, a sediment sampling point at the United States Navy Reserve dock in Lake Union, Seattle, Washington. This site has typical Fe concentrations on the order of $6.6 \%$. The lead concentrations are $1000 \mathrm{ppm}$ indicating a fair degree of freshwater runoff containing $\mathrm{Pb}$ from internal combustion engines. These spectra are not atypical of that seen in normally polluted sediments in the vicinities of large cities. An additional point to note from Figure 13 is that although Mo can be seen in the spectrum, the computer states that it is less than $50 \mathrm{ppm}$ Mo because the limit set on these data was at the $95 \%$ confidence level or 3 o limit. If one were to say, "Is Mo here?", a lower command on the statistics could be placed on the computer and the Mo concentration would then be detectable, al though not with high accuracy. Molybdenum was easily analyzed in sediments at Point Defiance (Figures 14, 15, Tabie 8) at concentrations of 30 and $50 \mathrm{ppm}$. Although this is relatively high for Mo in the environment, it has been seen before in this area of Puget Sound. (12)

The typical errors involved in the analysis in this evaluation using only $6 \mathrm{mCi} \mathrm{Cd}$ excitation follows: $8 \% \mathrm{Fe}$, error bars are $\pm 0.6 \%$, $\mathrm{Zn}$ and $\mathrm{Cu}$ at $1500 \mathrm{ppm}$, errors were typically $\pm 300 \mathrm{ppm}$. Lead concentrations at $1000 \mathrm{ppm}$ had inherent errors of $\pm 160 \mathrm{ppm}$. Strontium and $\mathrm{Zr}$ concentrations at $250 \mathrm{ppm}$ had errors of $\pm 30 \mathrm{ppm}$. One Mo sample, measuring $50 \mathrm{ppm}$, had an error of $\pm 8 \mathrm{ppm}$. In general, 
these errors would be considerably improved by longer counting periods and/or a more intense radioisotopic source.

Tables $9-12$ show the concentrations of elements in the sediments in marine and freshwater areas of the State of Washington as measured with the in-situ $X$-ray spectrometer. These data can be compared to data obtained in an earlier study as shown in Table 13. (12) In this study $\mathrm{Ca}$ and $\mathrm{Ti}$ were poorly detected by the in-situ spectrometer. Iron concentrations in surface sediment samples as determined by laboratory analysis agreed with in-situ analys is in the previous studies. Element concentrations varied as a function of depth; none of the . element concentrations as a function of depth were constant within $\pm 5 \%$--the precision of the measurement. None agreed completely with laboratory concentrations determined from grab samples obtained in the same sediment area. These variations can be seen in Figure 18 which illustrates the spectra obtained at one location; (12) the upper spectrum, obtained from an analysis of the sediment surface, contains $350 \mathrm{ppm}$ Mo while no Mo. is seen in the lower spectrum which is from the analysis of the sediment $2 \mathrm{~cm}$ below the surface. The $\mathrm{Pb}$ concentrations obtained in previous studies (12) in the ship canal are shown in Figure 19. The $A A^{\prime}$ line illustrates the concentration of $\mathrm{Pb}$ determined by laboratory $X$-ray fluorescence analysis of homogenized sediment obtained by grab sampling material at the site of the underwater analyses. The bar graphs show data obtained with the in-situ analyzer. As can be seen, the Pb concentrations are high at the surface, decrease at the 2 to $3 \mathrm{~cm}$ depth, and then increase gradually at greater sediment depths. The bulk sample contained material from depths greater than either 3 or $8 \mathrm{~cm}$, and thus it would seem that the average concentration as shown by the $A A^{\prime}$ line results from material 


\section{Pb CONCENTRATIONS AS A FUNCTION OF SEDIMENT DEPTH IN THE SHIP CANAL, WASH.}

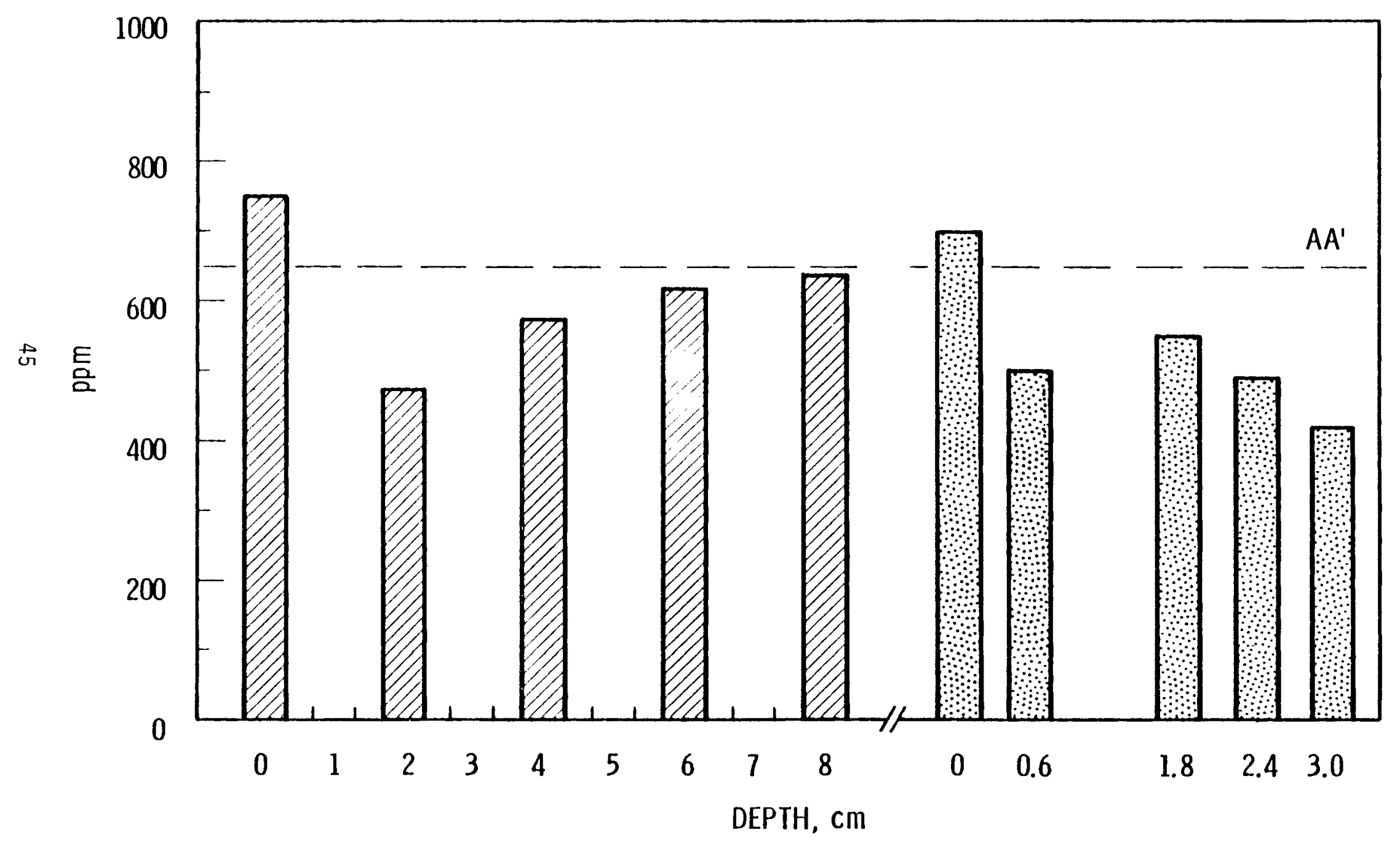


of greater concentration at greater depth than that measured by the in-situ spectrometer. This indicates that the spectrometer system should be designed to penetrate sediment depths greater than $8 \mathrm{~cm}$ in this area for proper total pollutant anaiysis. For most U. S. Coast Guard use, this depth profile capability is probably not required. Variations in the data from the present experiment may be explained by a flushing of the sediments since the last study of 1978 .

The data in Tables $9-12$ show pollutant concentrations of many elements, some of which are hazardous to man. The in-situ data in Table 9 shows the Pb concentration varying from $<330$ to $1000 \mathrm{ppm}$ for sediments, while Fe concentrations varied from 3.4 to $14 \%$. The highest $F e$ was associated with the lowest $\mathrm{Pb}$. Although Mn was not analyzed well in these experiments, Mn-Fe ratios provide a means of determining sample composition among successive sites, i.e., the typical rock type of the area. (13) More conservative elements such as $\mathrm{Rb}$, $\mathrm{Sr}$ and $\mathrm{Zr}$ illustrate that a material of a common type was, in general, being analyzed. For the purposes of this paper, an in-depth discussion of the meaning of the element ratios will be omitted since it is not germane to the discussion of instrument design or evaluation. Thus, it is just noted that elemental concentrations were detected which varied as a function of sediment location, and that the concentrations varied, in some cases, over :n order of magnitude. Strontium values are interesting in that they should reflect the marine environment and the calcium carbonate nature associated with that particular area (See Table 9) Data from Table 9 also show that As varies from $<70 \mathrm{ppm}$ to $1500 \mathrm{ppm}$ in sediments. Transition metal concentrations ( $\mathrm{Ni}, \mathrm{Mn}, \mathrm{Cu}$, and $\mathrm{Zn}$ ) also varied but not as much. Overall, the study illustrated that pollution from point sources is quite variable and that typical grab samples do not allow an analysis required to determine the areal extent of the pollutant element. As noted from 
this evaluation, the in-situ $X$-ray fluorescence analyzer did not supply all the required information. However, it did supply more information per unit time than would a laboratory analysis/grab sampling technique. Previous studies (12) using grab samples analyzed with laboratory techniques and the in-situ analysis demonstrate that point source analysis does not fulfill the need for determining the absolute areal distribution of pollutants. This can be accomplished only with a method developed for the analysis of elements over broad areas of sediment.

Elemental analyses of grab samples of the surficial sediment do not normally agree with the in-situ analyses. (12) Grab samples are obtained through the use of scoops; box corers, or divers who attempt to collect the top few $\mathrm{cm}$ of sediment surface where the pollutant just released should reside. The in-situ spectrometer analyzes the upper $1 \mathrm{~mm}$ of surface and therefore the recently deposited pollutant. The grab sample/laboratory analys is techniques analyze bulk material which does not represent the same sample that the in-situ system analyzed. This is unfortunate since it means that no good information can be obtained of recent pollutant concentrations in surficial sediments by grab sampling tecinology.

This select element data illustrate the fact that point source analyses will contain errors in estimating the amount of pollutant being distributed due to the inhomogeneity of the pollution. This error can be corrected only by developing a technique to continuously integrate element concentrations over broad sediment areas and waterways under study.

\section{SUMMARY}

In this study we have evaluated the practicality of in-situ $X$-ray fluorescence analysis for U. S. Coast Guard application. The spectrometer 
system measured major pollutant elements in sediment surfaces as well as in some water columns. Although most elements are measured at the 20 to $50 \mathrm{ppm}$ range, elements could be measured to $5 \mathrm{ppm}$ in both fresh water and marine ecosystems if a stronger excitation source than $6 \mathrm{mCi} 109 \mathrm{Cd}$ were used. The experiments also showed that upwards of 30 elements can be measured in-situ in sediments. The technology illustrated that sediment analys is is important in mapping the extent of pollution and in determining its areal concentration at the sediment-seawater interface. The evaluation showed that an instrument allowing continuous elemental analys is over broad areas would be the preferred method for pollution analysis. The in-situ probe monitors chemical compositions which are not detected by bulk sampling/laboratory analyses.

\section{RECOMMENDATIONS}

As illustrated by the existing evaluation, the in-situ X-ray fluorescence spectrometer can be a useful instrument for the U. S. Coast Guard in determining the spread of inorganic pollutants in sediments and water columns. However, a series of changes should be made to enhance the use of an $X$-ray fluorescence spectrometer system for these purposes.

- The radioisotopic source strength should be on the order of $100 \mathrm{mCi}$. In addition to $109 \mathrm{Cd}\left(\mathrm{t} \frac{1}{2}=453\right.$ days, 22 and $25 \mathrm{keV}$ photons, $102.3 \%$ ) used in the present study, three additional sources of irradiation would be required. The first is $241 \mathrm{Am}\left(t \frac{1}{2}=458\right.$ years) which emits 59.6 keV (35\%) photons and NpL $X$-rays 11.9 to $22.3 \mathrm{keV}(40 \%)$. The second is ${ }^{57} \mathrm{Co}$ which emits $122 \mathrm{keV}$ photons (85\%) and 6.40 and $7.06 \mathrm{keV}$ photons $(55 \%)$. A third radioisotope which would be useful is $153 \mathrm{Gd}$. ( $t_{\frac{1}{2}}=$ 242d) emitting 41.3 and $47.3 \mathrm{keV}$ photons (110\% per decay). The source 
arrangement of the new spectrometer system must be such that each source is rotated to its irradiation position remotely. In this fashion, the use of these radioisotopic sources in a simple carousel switched into a radiation position by small remote motors would allow all elements from $\mathrm{Ca}$ to $U$ to be analyzed with greater sensitivity than that achievable with just ${ }^{109} \mathrm{Cd}$ as used in the present study.

- The secondary Be window which is used on the existing spectrometer is built such that a variety of evaluation applications can be accommodated. For U. S. Coast Guard use, a combination Be window, collimator and source should be packaged on the spectrometer system such that it is an easily removable unit and would screw in and out, locking with respect to pressure.

- The spectrometer system designed for U. S. Coast Guard purposes should operate with $400 \mathrm{~m}$ cables. The specifications required of the vendor supplying the system should ensure that the complete package-cables, amplifiers and analyzer--have a specified resolution (i.e. $<200 \mathrm{eV}$ at $5.9 \mathrm{keV}$ ) and a limit on the microphonics in the cable. (No resolution degradation) Microphonics can be designed out of the system. The system should be designed with fewer neoprene 0-rings than used in the present spectrometer to eliminate the possibility of leaks. The cable which is used to lower the detector could be armored such that the electronic cable and lifting cable are common. It is suggested that the spectrometer manufacturer be required to use armored cable in his system check out such that noise isolation is vendor responsibility. 
- The underwater detector system must be designed as a towable "fish" for analysis of inorganic aqueous components with consideration given to its use for analysis of pollutant concentrations distributed at sediment surfaces.

- For use on U. S. Coast Guard boats, the spectrometer should have a quick disconnect liquid nitrogen dewar for refreezing the solid cryogen. In this fashion system handling would be simplified.

- In terms of the instrument package on board the vessel, it is suggested that instead of a simple hardwired analyzer/magnetic tape/laboratory computer, a system with a full software package and disc be used to provide immediate onsite onboard data reduction. Such an instrument package has been used by Battelle in other field program areas. Mini-computers have been used in submersibles and on oceanography vessels in severe marine environments and have allowed the exact determination of elemental concentrations with other spectrometer systems. A modern microprocessor can be used to record data directly from the spectrometer in foreground, while manipulating the data from the previous sample in background providing a readout description in concentration. In this fashion, one would obtain data at the same time sample analysis is being accomodated and thus maximize data output from a spectrometer system.

- It is suggested that a spectrometer including a full software package be obtained for data reduction onsite for use by the U. S. Coast Guard personnel. Software for the present Battelle system could be improved for specific uncerwater afplication to U. S. Coast Guard probiems. Computer program changes to optimize the measurement of sample matrix 
through scattering should continue to be developed to improve the element measurement accuracy of the matrix material being studied and thus its direct interpretation.

- A TV monitor would be valuable in clear water to view the sediment surface and the surroundings of the spectrometer. It most likely would be inoperable in polluted harbors due to a lack of visibility. This latter type of system has been used by Battelle-Northwest in underwater viewing in clear ocean areas off the coast of Florida. However, the use of a TV monitor in areas such as Long Island Sound cannot be accomplished due to the heavy sediment load in the water column.

- In summary, it is recommended that additional laboratory and field studies be accomplished. The laboratory studies should contribute design information for construction of a probe for the specific needs of the U. S. Coast Guard, a probe which will act as a "fish", analyze material on the boat, or act as a sediment analysis system which will be towable. Additional studies are required to achieve absolute automation of the analyses since the present system requires an interaction between the investigator studying the spectrum and the computer. This can be eliminated by additional software and matrix problem studies. Finally, these programs should be evaluated in field studies in clear water areas where one can place standards of interest on the ocean floor and test analysis software with the existing in-situ system. In this fashion, it is recommended that the present in-situ system be evaluated in clear, warm water areas for pollutants placed in real harbor situation conditions to maximize the efficiency of the software package. Additional design considerations should be evaluated under field conditions during this 
latter experiment. Following these field and laboratory studies, a prototype in-situ $X$-ray fiuorescence system designed for $U$. S. Coast Guard purposes should be constructed. It is expected that such a system would presently cost on the order of $\$ 30,000$ for the detector head, underwater preamp and fish. Armored cable would cost an additional $\$ 5,000$. For small boat operation armored cable could not be used due to the mobile winch required. An additional $\$ 50,000$ is required in the analysis system (electronic system). It is estimated that the laboratory and field studies required to complete design of such a system for U. S. Coast Guard use would involve a one-year research program at the $\$ 100 \mathrm{~K}$ per year level based on 1979 dollars. 


\section{ACKNOWLEDGMENT}

The author wishes to express his appreciation to R. M. Campbell, J. H. Reeves and D. R. Edwards of Battelle-Northwest, whose assistance proved invaluable in the completion of this program. Special thanks go also to Dr. Helen McCammon and Dr. W. O. Forster of the U. S. Department of Energy who funded the original development of the in-situ $X$-ray fluorescence system. 


\section{REFERENCES}

1. The Planners Dilema, Marine Poilution Bulletin 3, \#4, April 1972.

2. Oceans 76. Joint Conference of the Marine Technology Section of the Institute of Electrical and Electronic Engineers, September 13-15, 1976.

3. Bertine, K. K. and E. D. Goldberg. "Fossil Fuel Combustion in the Major Sedimentary Cycle." Science 173, p. 233, 1971.

4. Jaklevic, J. M. and F. S. Golding. "Semi-Conductor Detector X-ray Fluorescence Spectrometry Applied to Environmental and Biological Analysis." IEEE Transactions, Nuclear Science 26, $\# 3$, p. 384, 1972.

5. Rhodes, J. R., A. H. Pradzynski, and R. D. Sieberg. "Energy Dispersive X-ray Emission Spectrometry for Multielement Analysis of Particulates." Proceedings of the 18th Annual ISA Analys is Instrumentation Symposium, San Francisco, p. 143, May 1972.

6. Wogman, N. A. and K. K. Nielson. "In-Situ Parts-per-Million Analysis of Submarine Sediments by $X$-ray Fluorescence Techniques." Proceedings of Joint Conference of the Marine Technology Society of the Institute of Electrical and Electronics Engineers, Paper 12-A, September 13-15, 1976.

7. Nielson, K. K. "Matrix Corrections for X-ray Fluorescence Analysis Using Scattered X-rays." Analytical Chem. 49, pp 641-648, 1977.

3. Rieck, H. G., Jr., J. R. Kosorok, R. W. Perkins, and N. A. Wogman. InSitu X-ray Fluorescence System Design. BNWL-B-394. Battelle-Northwest, Richland, Washington, Aprit 1975.

9. Wogman, N. A., H. G. Rieck, Jr., and J. R. Kosorok. "In-Situ Analysis of Sedimentary Pollutants by X-ray Fluorescence." Nucl. Instrumen. and Meth. 128, pp 565-568, 1975.

10. Pacific Northwest Annual Report for 1978 to the DOE Assistant Secretary for Environment, Part 4, Physical Sciences, PNL-2850, Battelle-iNorthwest, Richland, Washington, February 1979.

11. Cooper, J. A., H. L. Nielson, N. A. Wogman, and R. W. Perkins. "Feasibility Study of In-Situ Sediment Analys is by X-ray Fluorescence." Nucl. Tech. 26, pp 224-231, 1975.

12. Wogman, N. A., and K. K. Nielson. Develooment and Application of an InSitu $X$-ray Fluorescence Spectrometer for Underwater Sediment Analys is. PNL-SA-7199, Battelle, Pacific Northwest Laboratories, Richland, Washington 99352.

13. Mason, B. Principles of Geochemistry. Third Ed. John Wiley \& Sons, New York, Chapter 3, 1966. 
PNL -3168

$U C-11$

\section{DISTRIBUTION}

No. of Copies

OFFSITE

A. A. Churm

DOE Patent Division 9800 S. Cass Avenue

Argonne, IL 60439

27 DOE Technical Information Center

10 U. S. Coast Guard

Dr. Robert Hildebrand

U. S. Coast Guard Research and Development Center

Avery Point

Groton, CT 06340
No. of Copies

ONSITE

15 Pacific Northwest Laboratory

R. W. Perkins (1)

N. A. Wogman (7)

Technical Information (5)

Publishing Coordination (2)

DOE Richland Operations

H. E. Ransom 
